This article has been scanned by iThenticat No plagiarism detected

Volume 3, Issue 4, August 2021

p. $101-112$

\title{
THE EFFECT OF SUGGESTED TRAINING PROGRAM ON THE DEVELOPMENT OF ACADEMIC WRITING AT AL BURAIMI UNIVERSITY COLLEGE IN THE SULTANATE OF OMAN
}

http://dx.doi.org/10.47832/2757-5403.4-3.9

\section{Mohammed Saleh ALAJMI ${ }^{1}$ \& Samah Khamis Said AL MAMARI ${ }^{2}$}

\begin{abstract}
:
The current study aimed to build a proposed training program to advance the development of functional writing skills of Al-Buraimi University College students and measure its impact on improving functional writing skills. It also aimed to reveal whether there are statistically significant differences at the level of (a 0.05) in the level of acquisition of the college's students in the functional writing skills attributed to the human gender variable. To achieve the objectives of the study, the researchers used the approved semi-experimental approach based on the design of (one group with two pre and posttests). Therefore, a number of research tools and materials were designed, which are: a list of appropriate functional writing skills for students of Al-Buraimi University College in the Sultanate of Oman, an analytical assessment list for correcting the functional writing test, a pre and post-test for Al-Buraimi University College students, and building a training program for Al-Buraimi University College students in light of the list Specific skills, preparing the training program guide, and after verifying the validity and reliability of the research tools and materials, they were applied to a sample of (80) students at Al-Buraimi University College. The results of the study indicated a clear improvement in the growth of job writing skills in favor of the post test, as the average performance was $25.74 \%$, while the pre-test was $17.89 \%$. This indicates that students who underwent the experimental program based on constructivist theory in teaching had better functional writing skills.

This result indicates that the targeted functional writing skills have clearly developed among the students of Al-Buraimi University College, while the results of the second question showed that there are no

\footnotetext{
${ }^{1}$ Dr. , Suhar University, Sultanate of Oman, Majmi3@su.edu.om, https://orcid.org/0000-0002-6882-7608

${ }^{2}$ Researcher, Buraimi University College, Sultanate of Oman, samah@buc.edu.om, https://orcid.org/0000$\underline{0001-5397-7024}$
}

Copyright (C) Published by IJHER Journal, www.ijherjournal.com Rimar Academy, Fatih, Istanbul, 34093 Turkey 
differences in the level of students' acquisition of functional writing skills between males and females of Al-Buraimi College. In light of the results of the current study, we reached to the following recommendations: Benefiting from the list of functional writing skills that the current study reached by evaluating the performance of AlBuraimi University College students for the functional writing skills in light of it, and by building tests in light of that list and providing lecturers who teach the Arabic language course and list the skills so that they have a support in implementing the course with better efficiency.

While the study made some proposals, that are: Conducting a descriptive study to determine functional writing skills in universities and colleges in other areas, such as: writing reports, meeting minutes, resumes.

Key words: Training Program, Functional Writing, Al-Buraimi College, Sultanate of Oman.

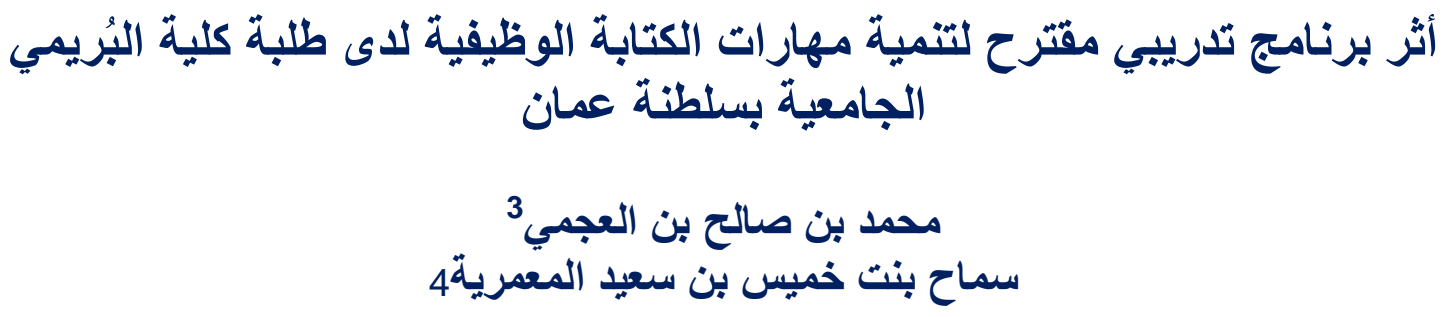

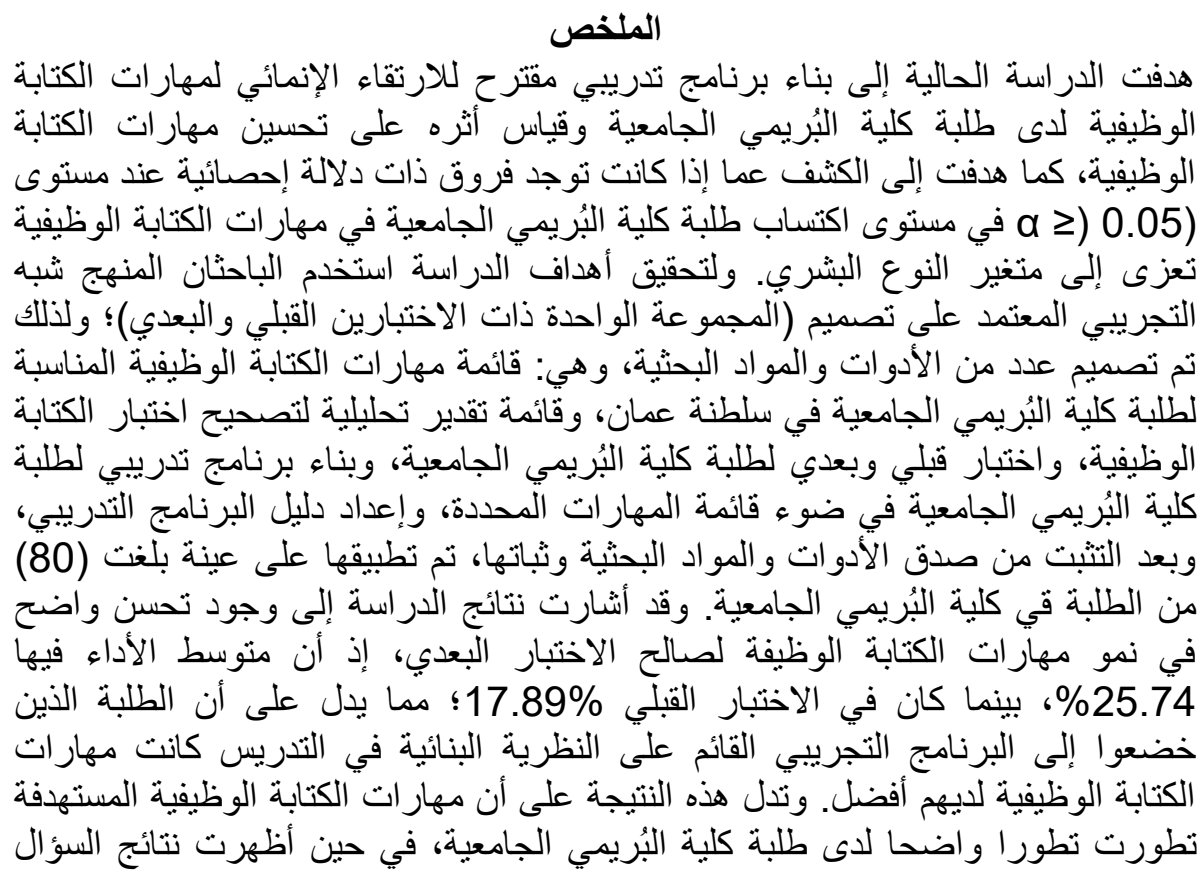

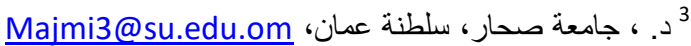
samah@buc.edu.om الباحثة، كلية البريمي الجامعية ، سلطنة عمان، 
الثاني عدم وجود فروق في مستوى اكتساب طلبة كلية البُريمي الجامعية لمهار ات الكتابة الوظيفية بين الذكور و الإناث.

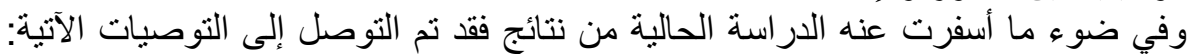

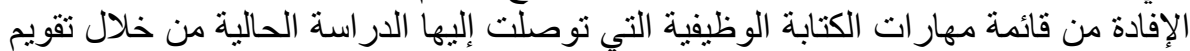

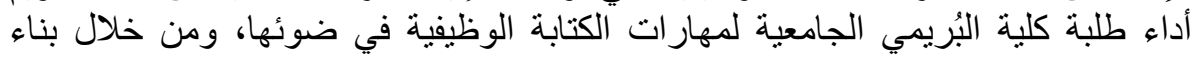

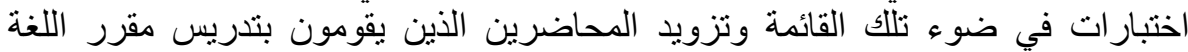

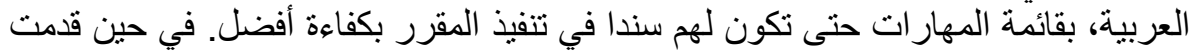

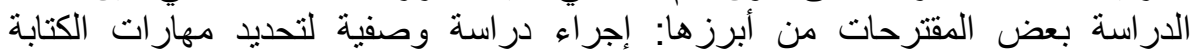

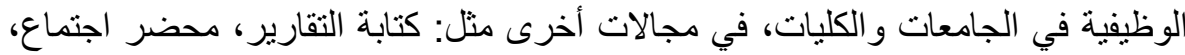

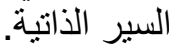

الكلمات المفتاحية: برنامج تدريبي، الكتابة الوظيفية، كلية البُريمي، سلطنة عمان.

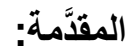

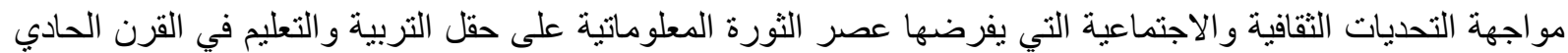

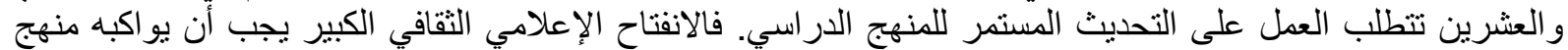

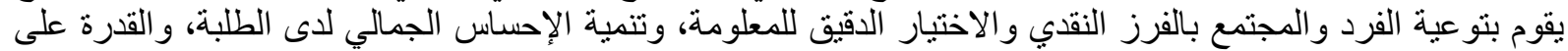

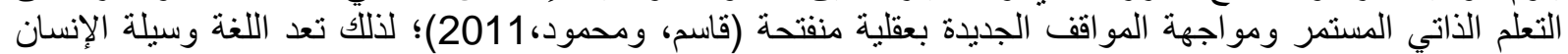

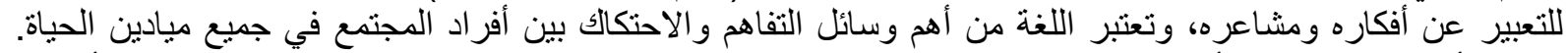

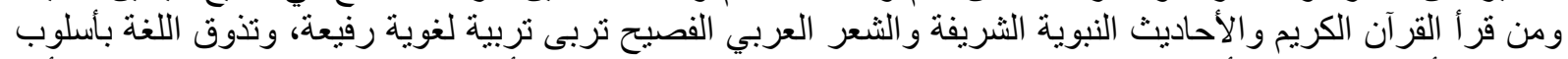

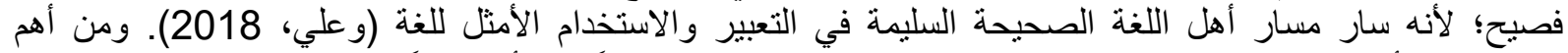

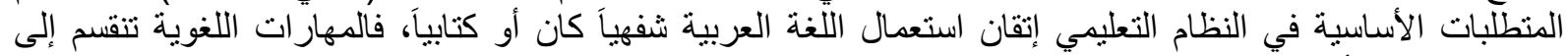

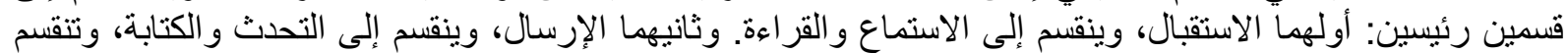

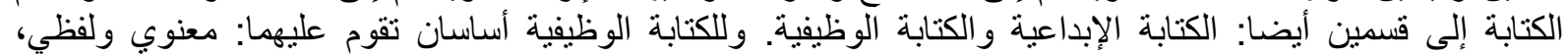

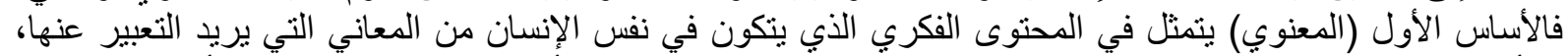

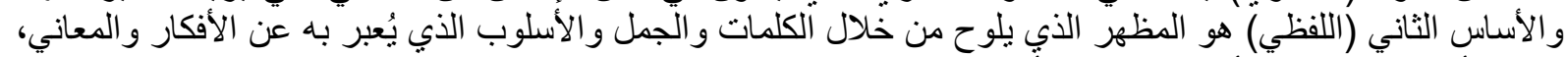

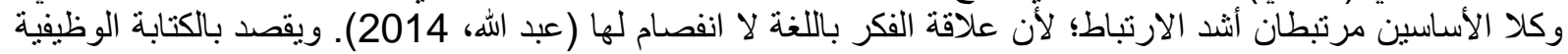

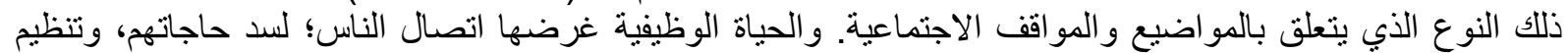

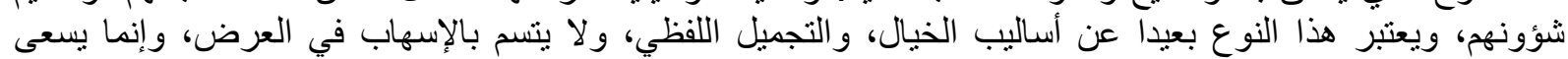

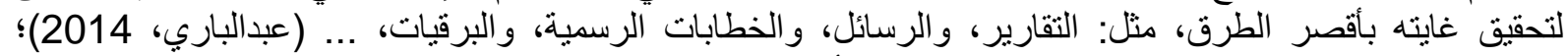

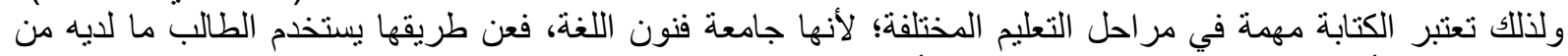

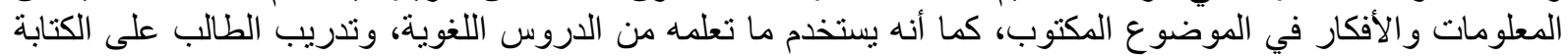

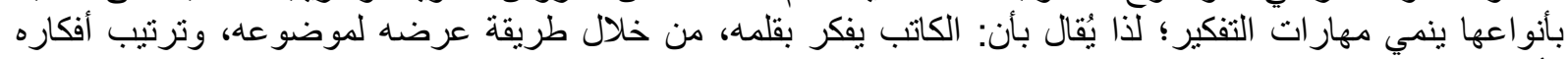
و وأسلوبه. وفي هذا الصدد تم عقد مؤنمر ات، وندوات، وأجريت دراسات، وبحوث؛ لتأكبد أهمية الكتابة الوظيفية، منها الندوة الثالثة

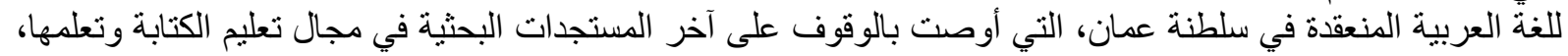

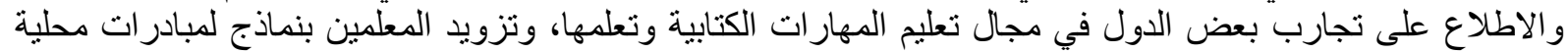

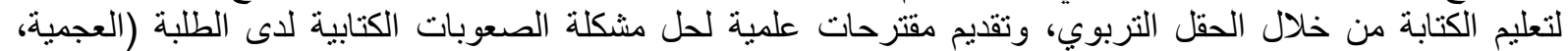

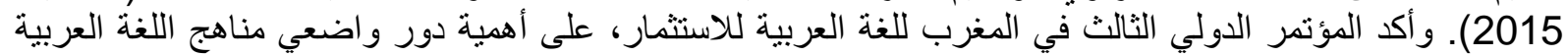

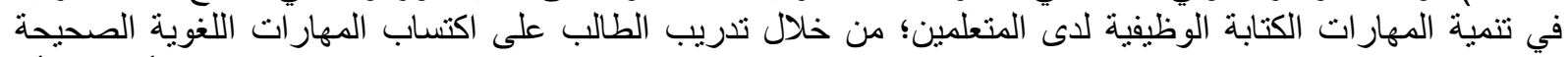

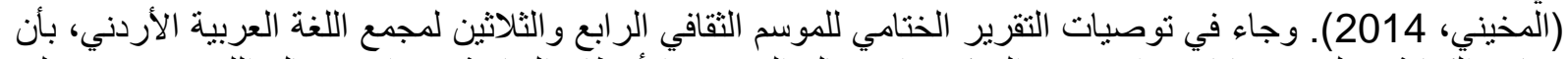

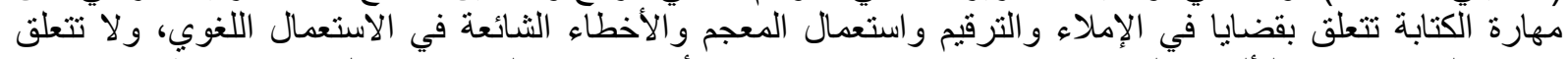

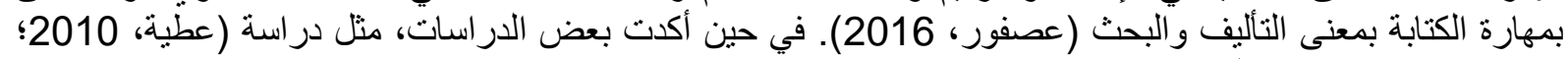

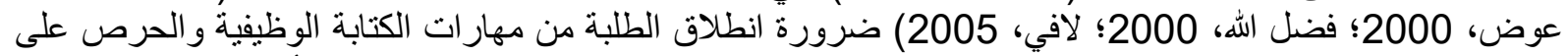

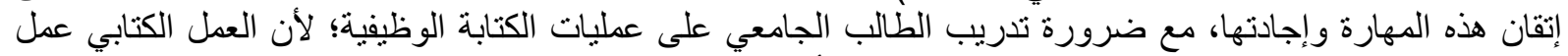

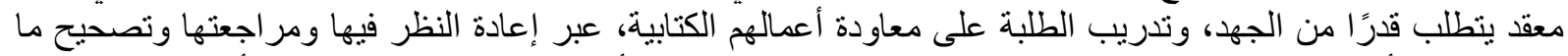

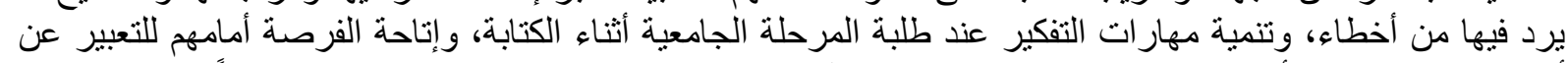

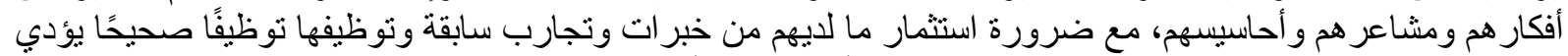

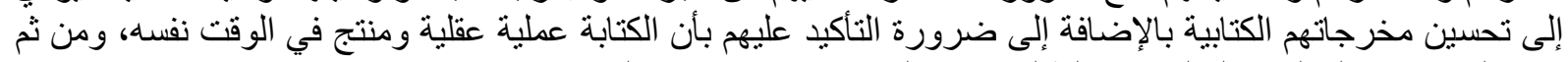
فإنه كلما ارتقت العمليات العقلية عند الطالب قادته إلى منتج كتابي بديع (الحامدي، 2012). 


\section{THE EFFECT OF SUGGESTED TRAINING PROGRAM ON THE DEVELOPMENT OF ACADEMIC WRITING AT AL BURAIMI UNIVERSITY COLLEGE IN THE SULTANATE OF OMAN}

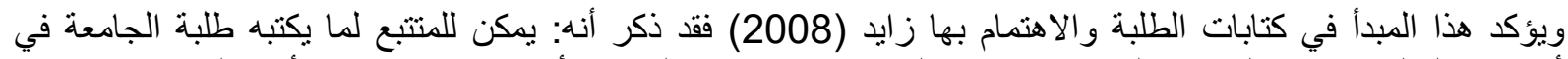

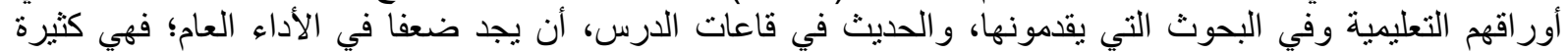

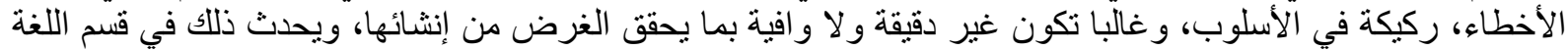

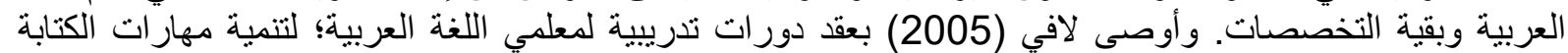
الوظيفية، وتقديم الحو افز المادية والمعنوية للطلبة المتفوقين في التعبير الكتابي، وعقد مسابقات في في التئية التعبير الكتابي الوظيفي

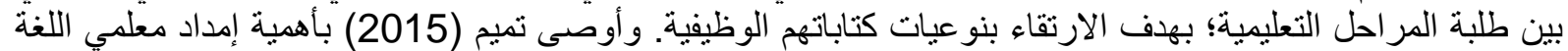

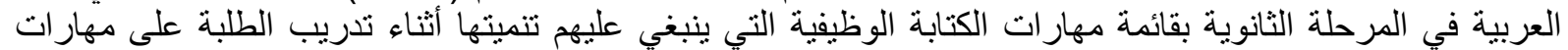

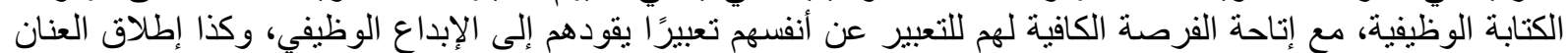

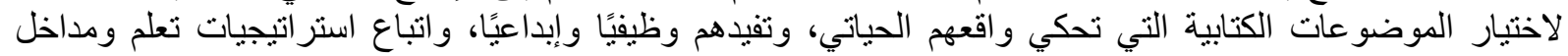

تدريسية حديثة عند تعليمهم للكتابة الوظيفية.

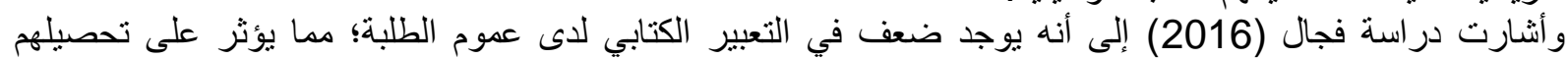

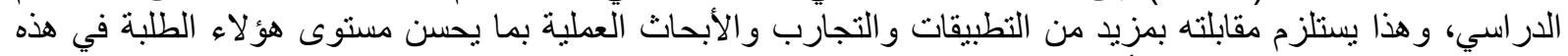

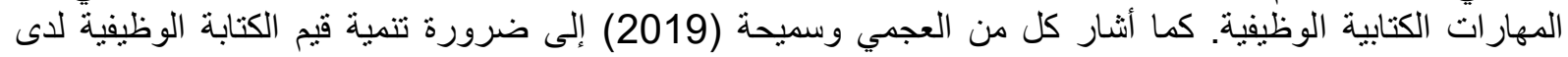

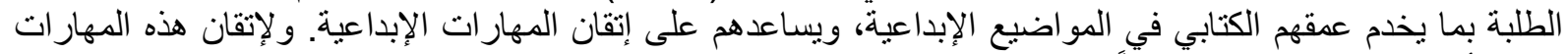

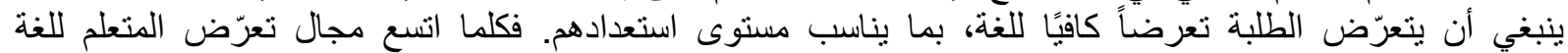

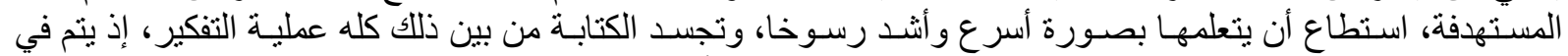

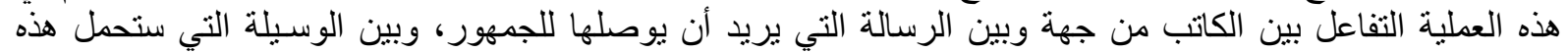

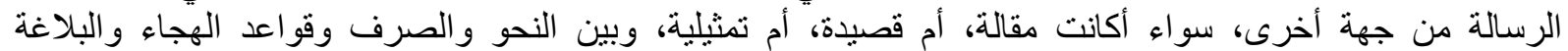

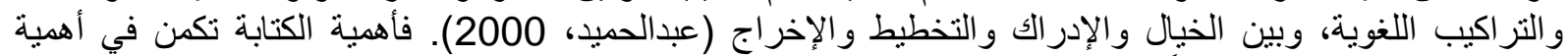

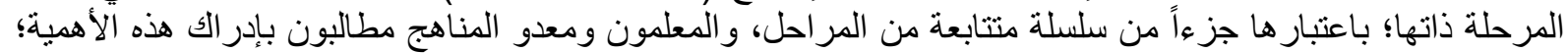

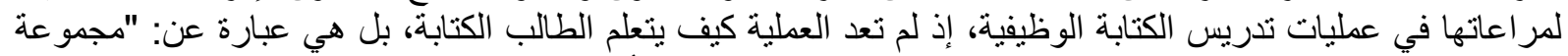

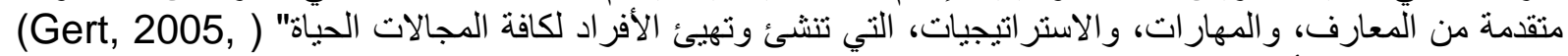

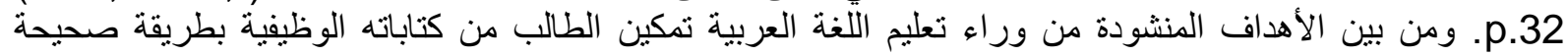

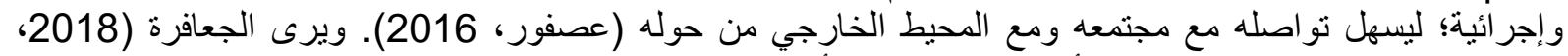

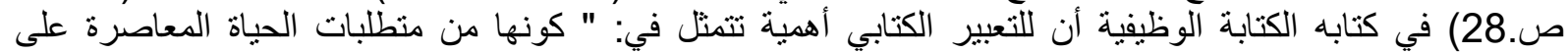

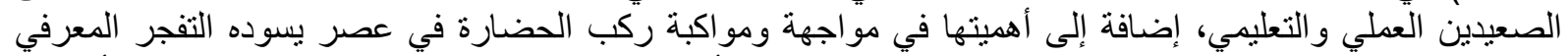

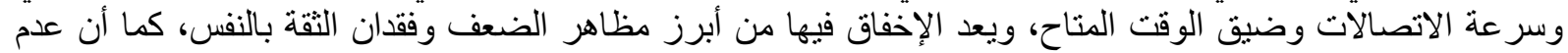

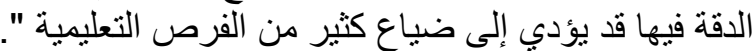

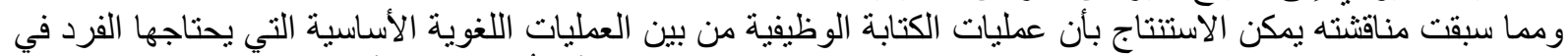

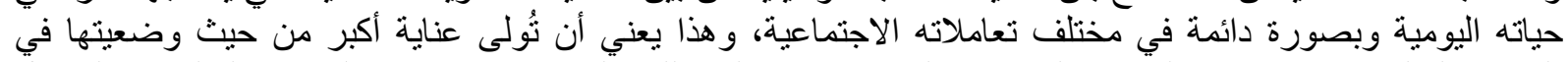

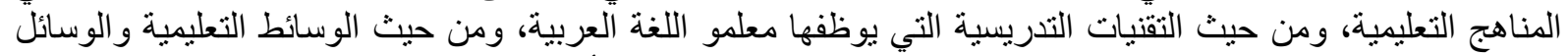

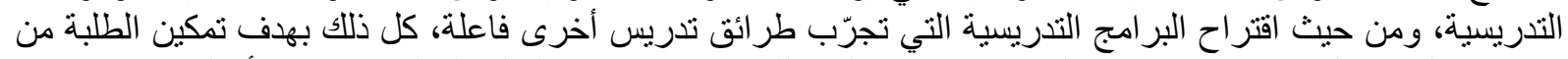

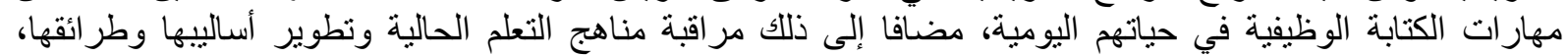

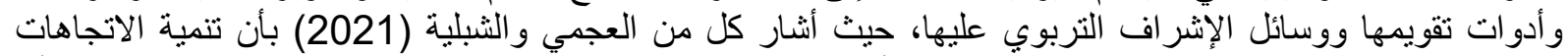

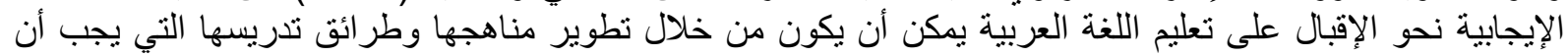

تفاعلية.

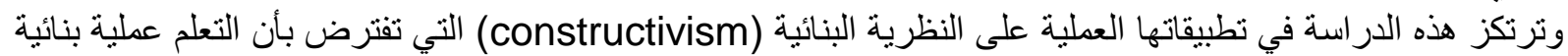

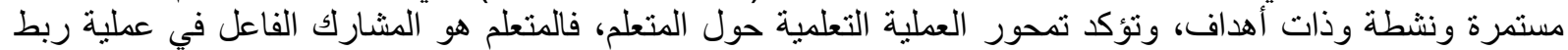

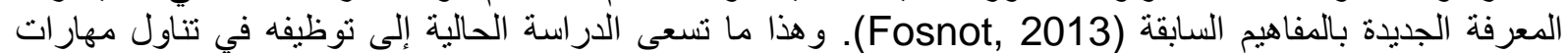
الكتابة الوظيفية، من خلال تدريس المهار ات الأساسية للكتابة الوظيفية في إطار بنائي.

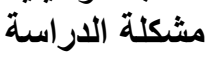

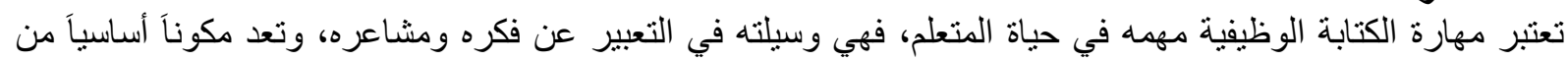

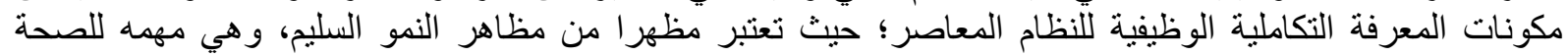

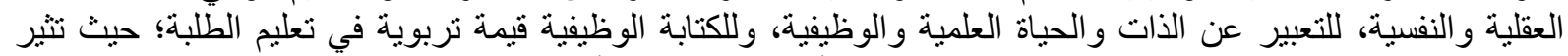

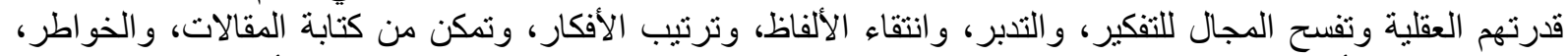

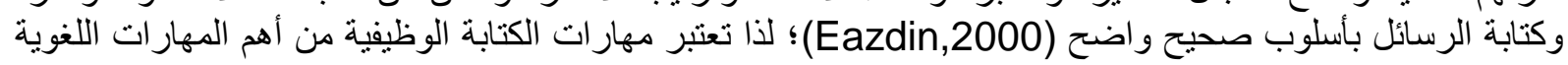




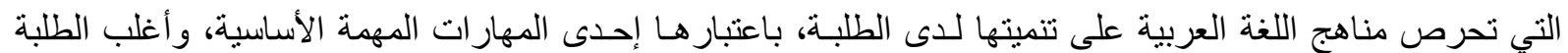

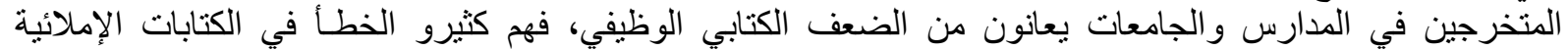

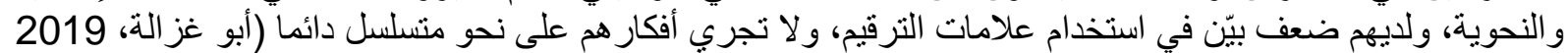

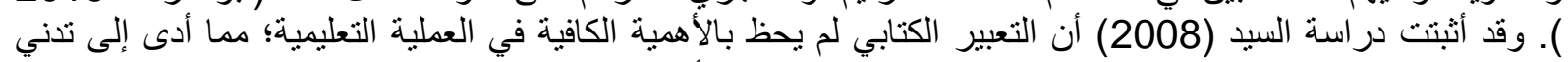

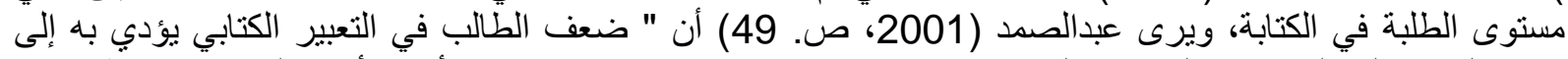

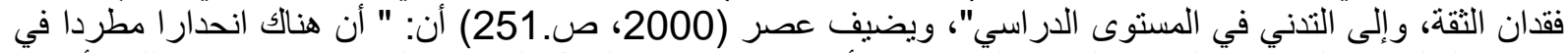

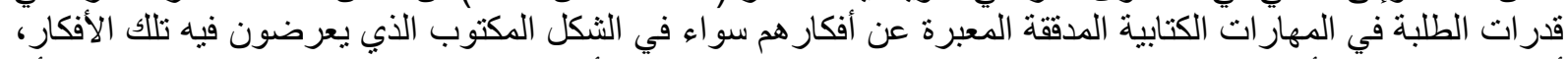

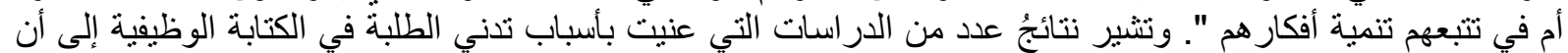

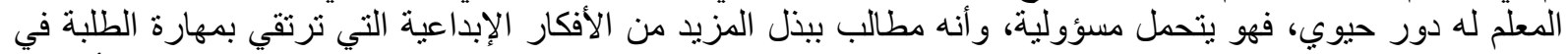
التعبير الوظيفي (تميم، 2007؛ فئ فيدالو هاب، 2002؛

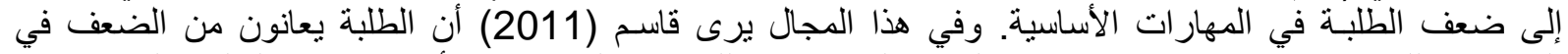

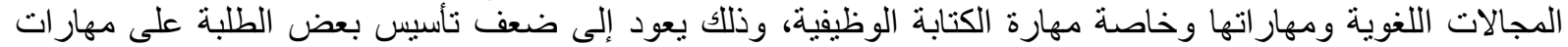

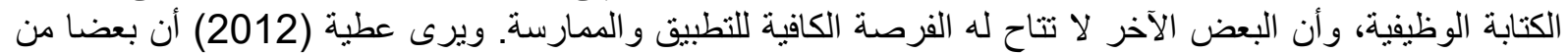

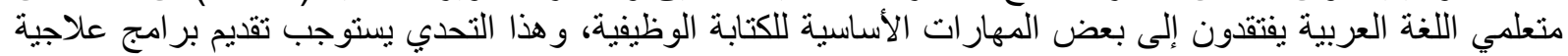

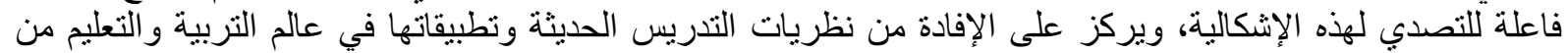

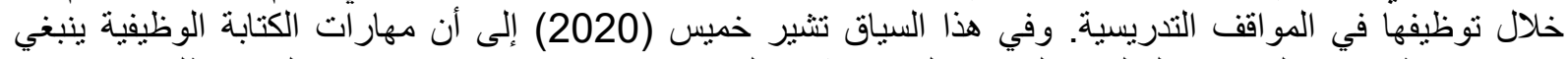

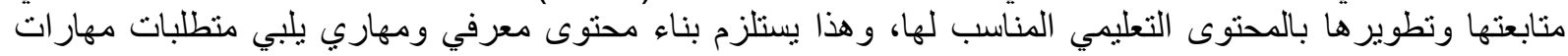

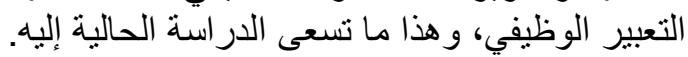

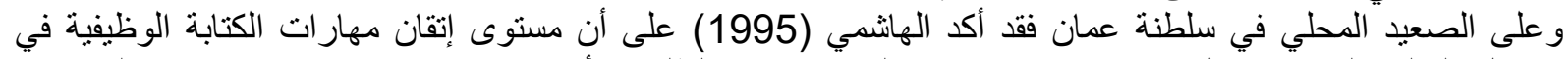

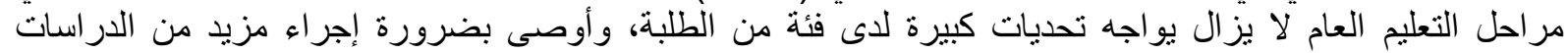

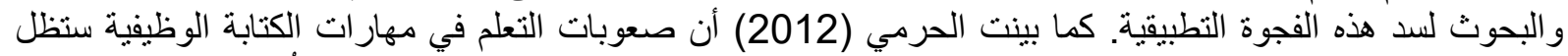

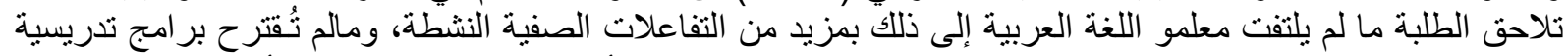

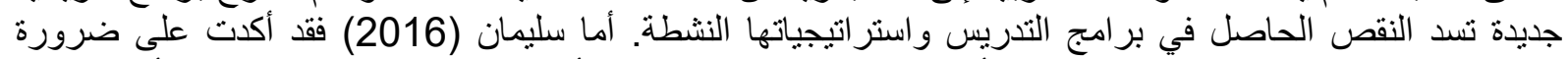

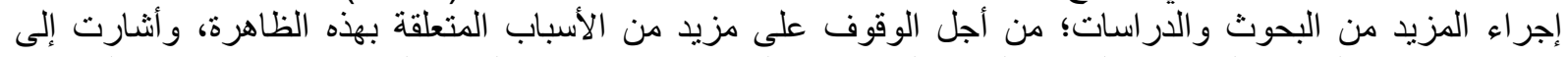

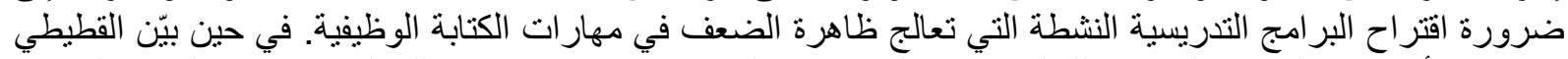

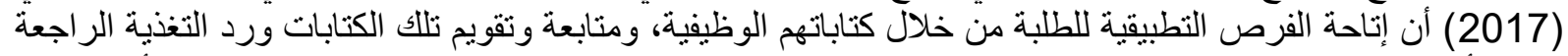

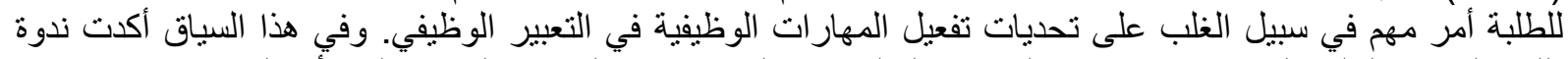

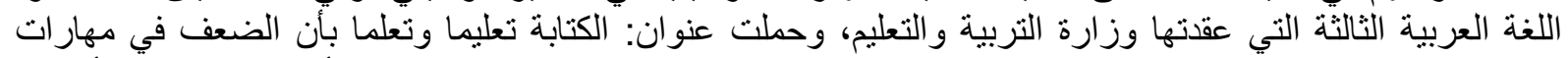

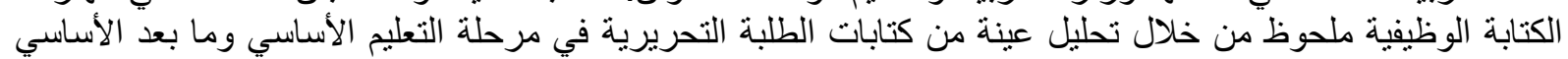

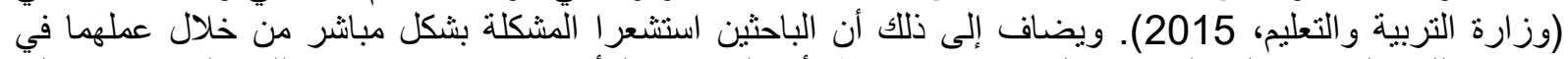

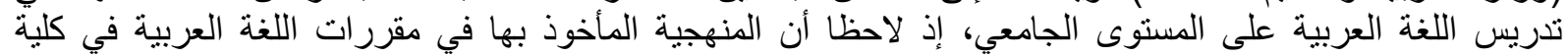

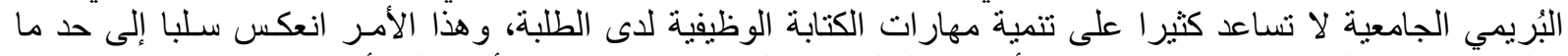

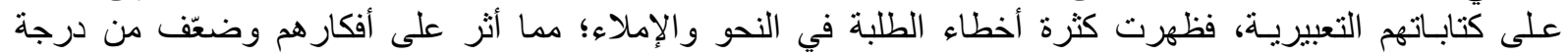

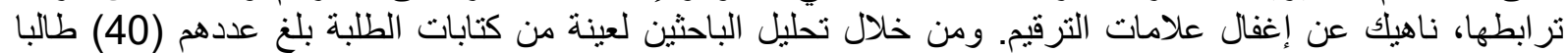

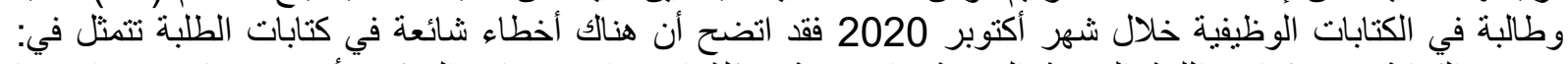

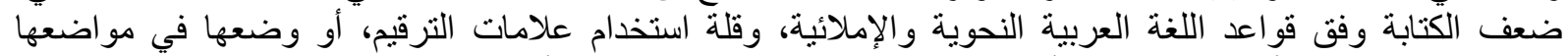

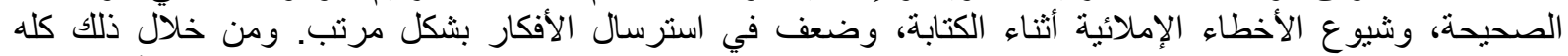

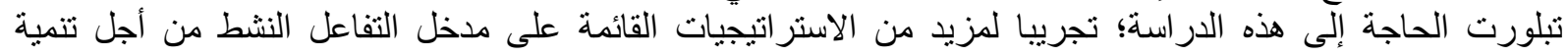

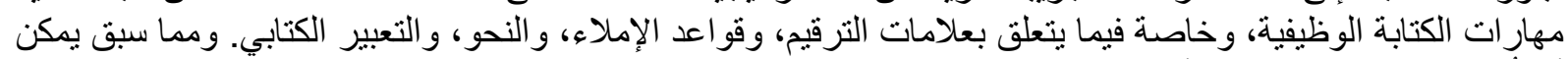

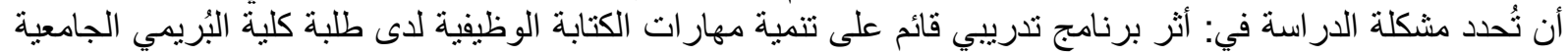

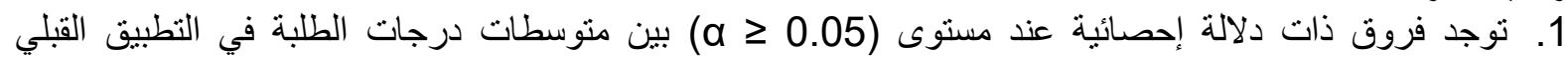

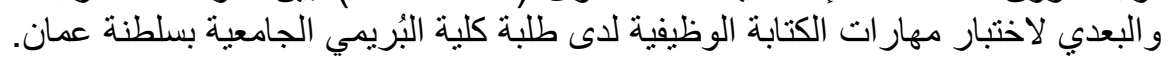

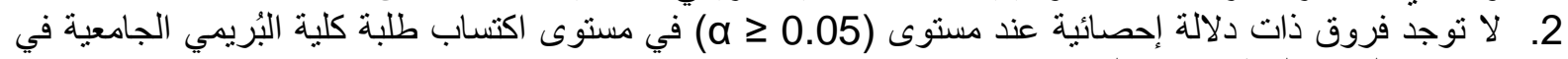
مهار ات الكتابة الوظيفية بين الذكور و الإناث.

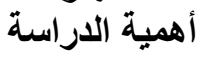

يتوقع أن تسهم الدراسة الحالية في ميدان تعليم اللغة العربية للطلبة الجامعيين من خلال:

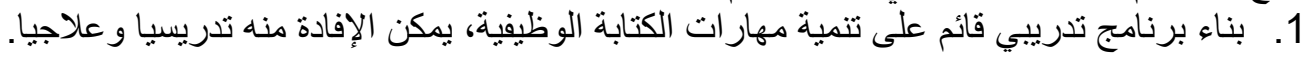


2. إفادة أساتذة الجامعات والكليات باستخدام استر اتيجيات جديدة قائمة على النظرية البنائية لتعليم الطلبة مهارات الكتابة الوظيفية.

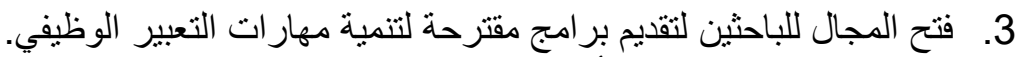
4. إمكانية وضع هذه الدراسة أمام مخططي المناهج اللغة العربية؛ لعلها تسهم في تطوير تعلم مهارات الكتابة الوظيفية. أهداف الار اسة الكة

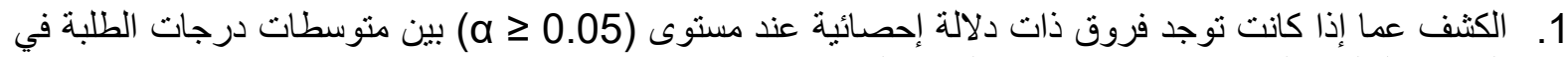

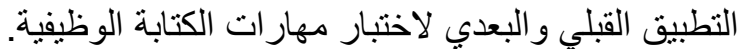

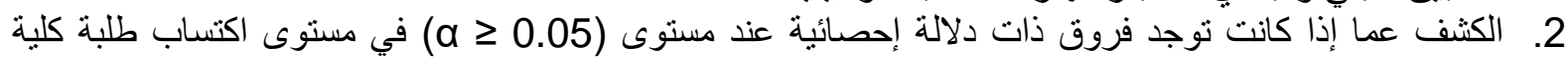

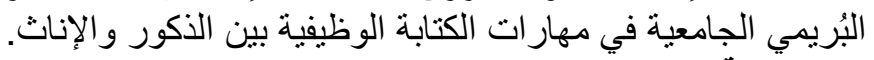

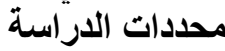
1. الحد الزماني: طبقت الدراسة في الفصل الدراسي الثاني من العام الأكاديمي (2019-2020). 3.

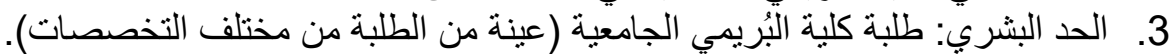

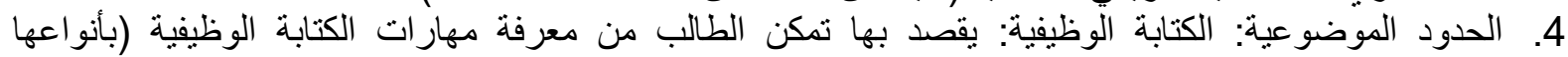

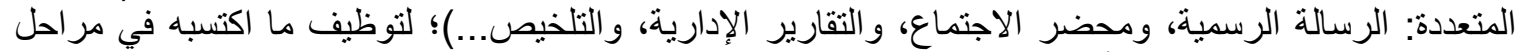
دراسته الجامعية، و التعبير عن أفكاره في سوق الرعل، العمل، وميادين الحياة المختلفة. التعريفات الإجرائية

1. المَهَارة بالقتح: "السهولة والدةقة فئة في أداء عمل من الأعمال، وتتطور نتيجة لعملية التعليم، وهي القيام بعملية معينة

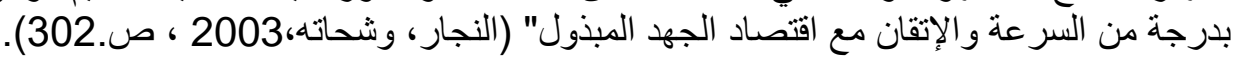

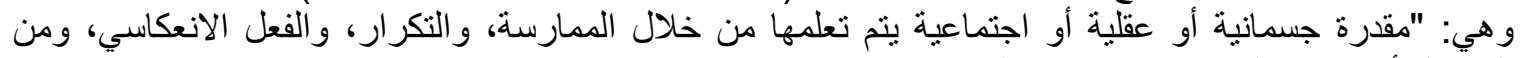

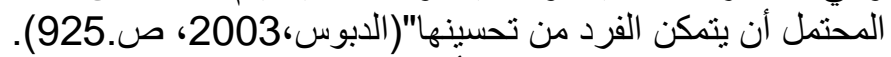

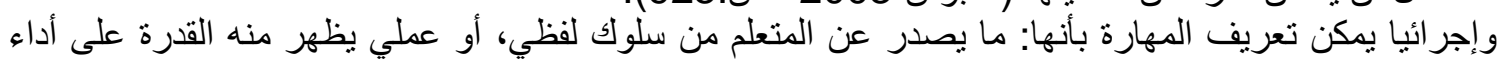

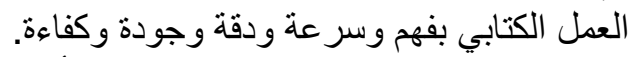

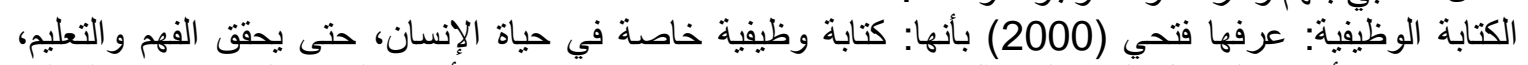

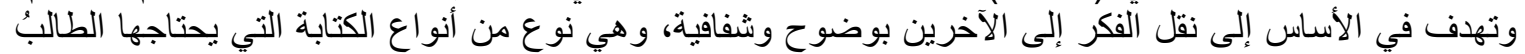

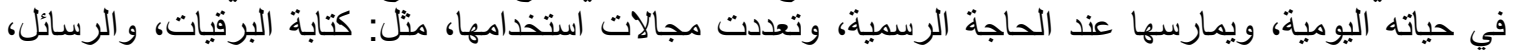

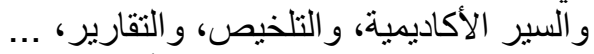

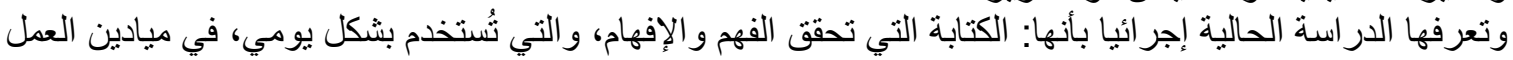

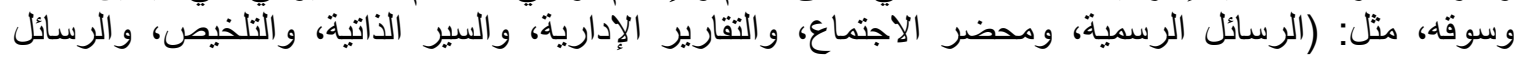
الإلكترونية). منهج الدراسة الأنئة المنهج شبه التجريبي (المجمو عة الواحدة ذات الاختبارين القبلي و البعدي) وفق تصميم الاختبار القبلي.

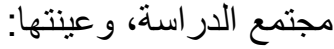

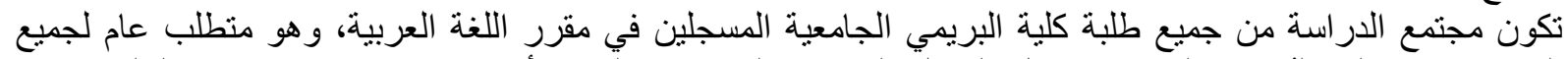

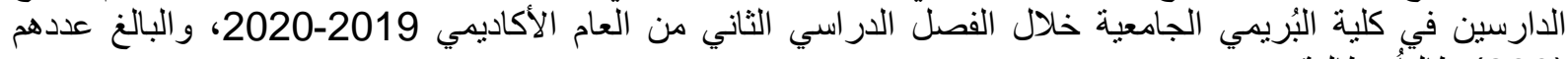
(280) الباً وطالبة. عينة الدراسة (مالة

أما عينة الدراسة، فتم اختيار ها وفق الخطو ات الآتية: 1. تحديد جميع الطلبة المسجلين في مقرر اللغة التئة العربية.

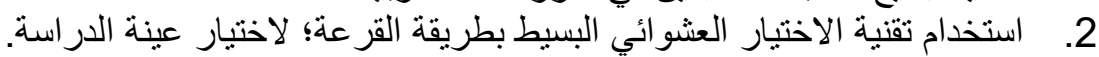

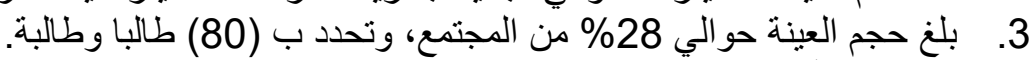
متفيرات الاراسة

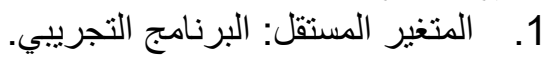

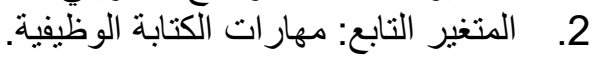




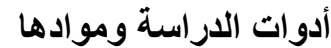

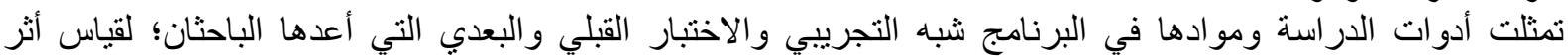

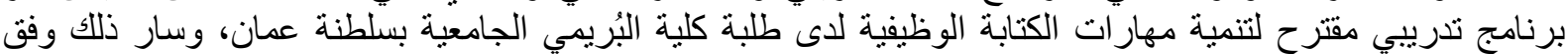
الخطوات الآتية:

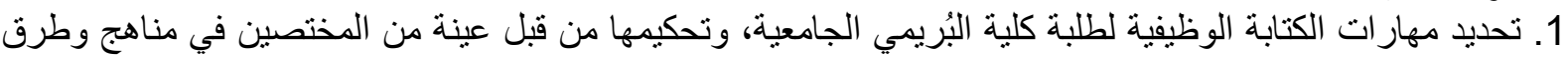

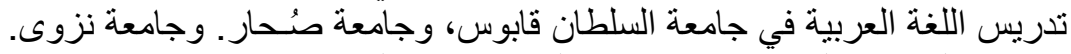

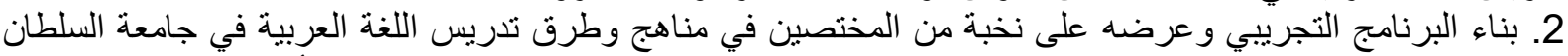

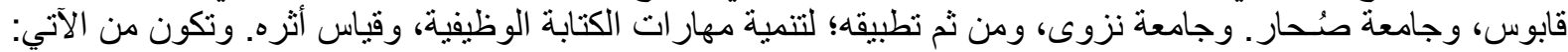

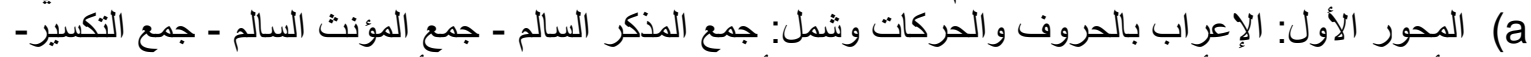

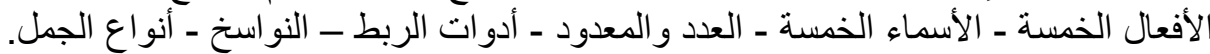

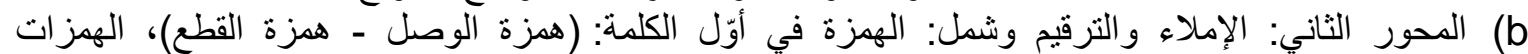

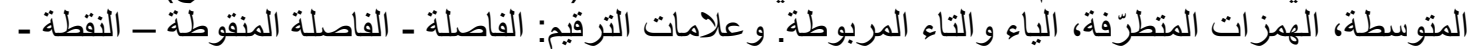

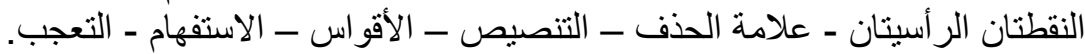
(c) المحور الثالث: فنون الكتابة الوظيفية، وشمل: فن الرسالة: تعريف بالرسالة، أنواع الرسائل، محضر الاجتماع: تعريف المحضر ، و عناصر ها.

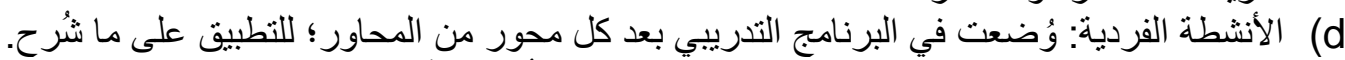

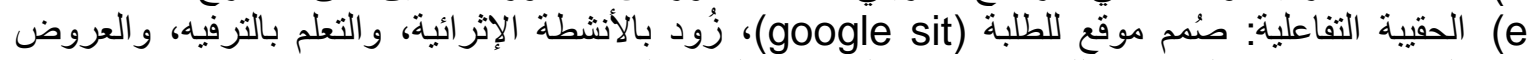

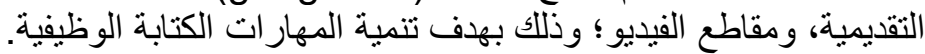

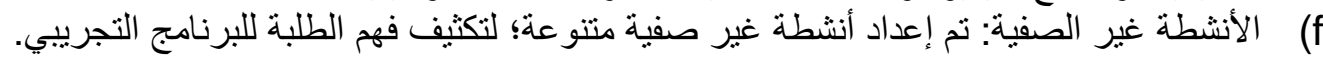

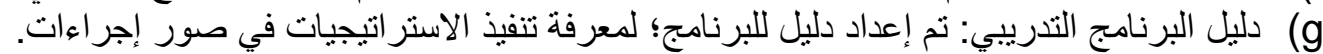

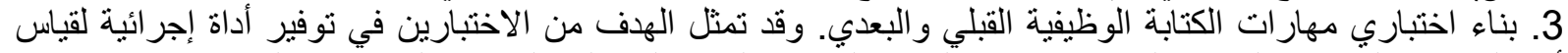

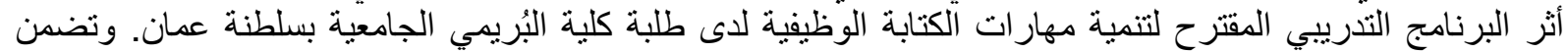

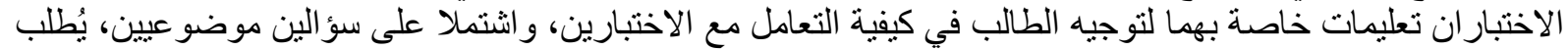

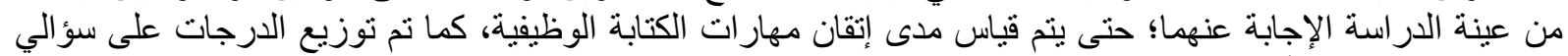

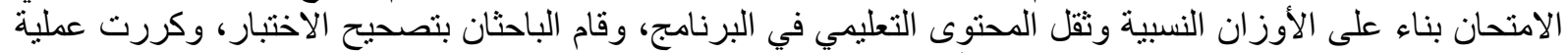

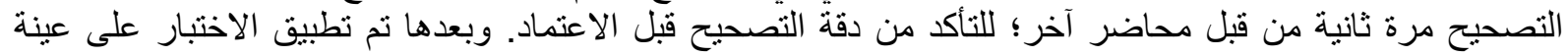
استطلاعية مكونة من (30) طالبا وطالبة من غير عيدة فينة الدراسة، بهدف التحقق من درجة الصعوبة والتمييز، وتحديد

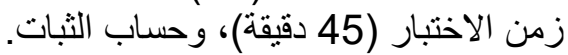

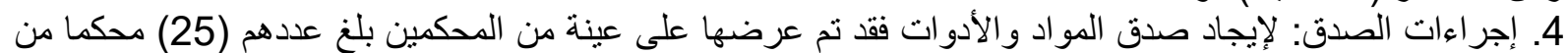

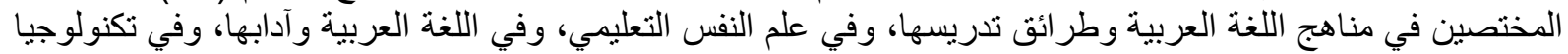

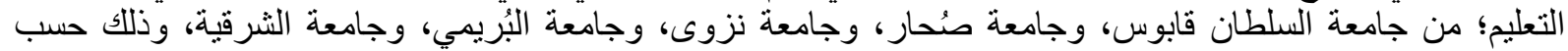

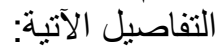

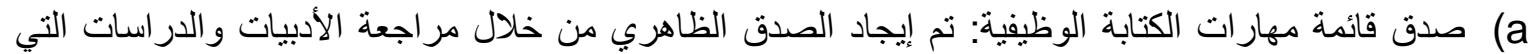

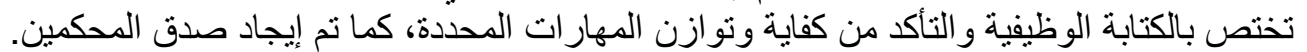

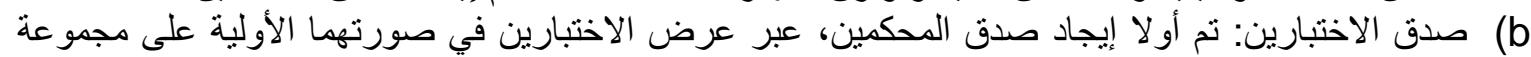

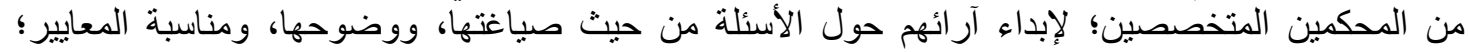

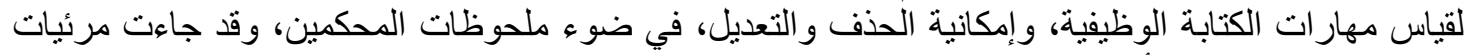

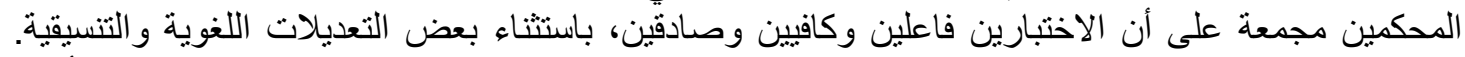

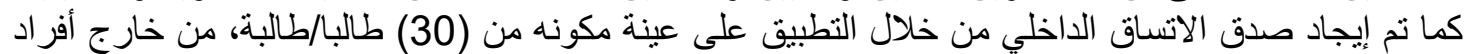

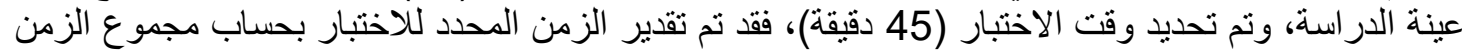

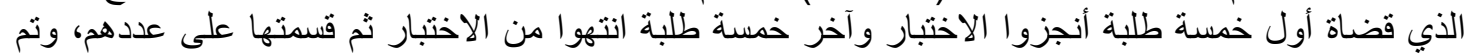

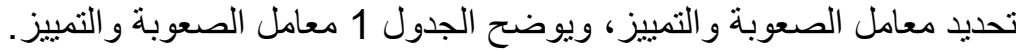
معامل الصعوبة والتمييز بين الاختبارين القبلي و البعدي

\begin{tabular}{|c|c|c|}
\hline البعدي & القبلي & الاختبار \\
\hline$\% 85$ & $\% 59$ & معامل الصعوبة \\
\hline 1.00 & 0.57 & معامل التمييز \\
\hline
\end{tabular}

يوضح الجدول 1 معامل الصعوبة في الاختبارين القبلي والبعدي، حيث تشير النتائج إلى تحسن نتائج الاختبار البعدي

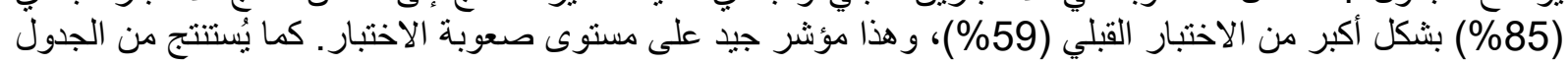


1 أن معامل التمبيز في الاختبار القبلي يبلغ (0.57) بينما في الاختبار البعدي (1)، وهذا يدل على أن معامل التمييز لاغختبارين جيد. أ) إعداد القائمة التقديرية التحليلية لتصحيح اختبار الكتابة الوظيفية. تم إعداد القائمة؛ لأنه من المهم الارتكاز على التهلى معيار

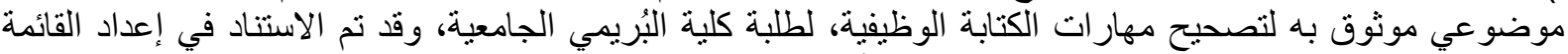

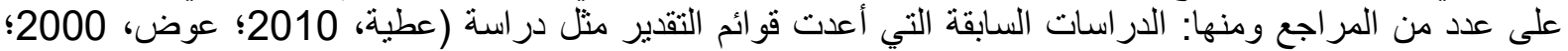

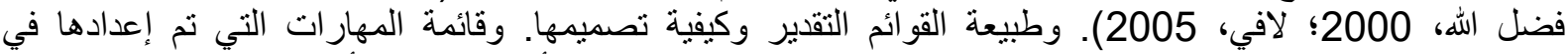
الدراسات السابقة. تم عرض القائمة على المحكمين المشار إلى تخصصاتهم أعلاه. وكانت أراء المحكمين حيالها جيدة و وأنها كافية وو افية. ب) صدق البرنامج: جرى التهانة التحقق من صدق البرنامج التدريبي من خلال عرضه على المحكمين من ذوي الخبرة في

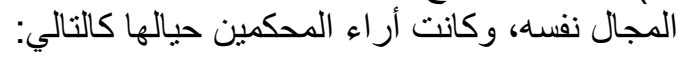

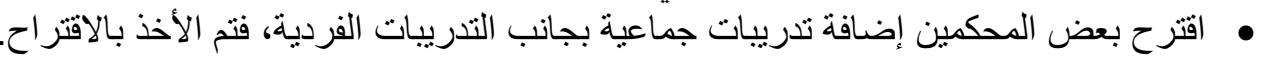

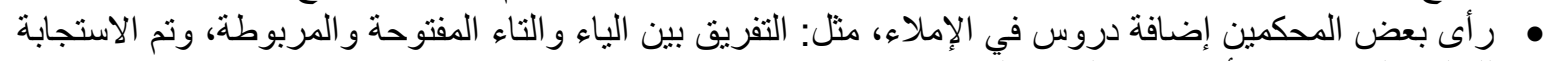
للطلب؛ لما فيها من أهمية في الكتابة الوظيفية الوفية.

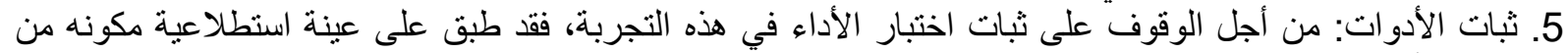

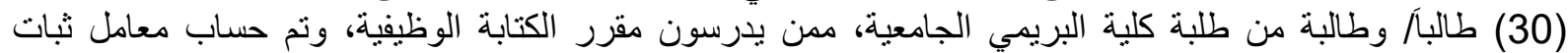

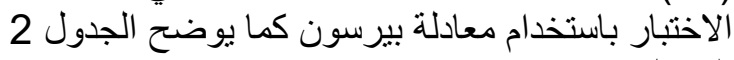
الجدول 2 ثبات اختبار مهار ات الكتابة الوظيفية

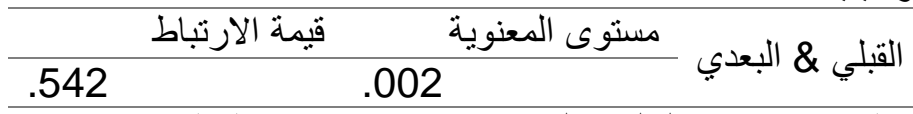

يوضح جدول 2 معامل الارتباط بين الاختبار القبلي والبعدي، حيث يوجد ارتباط طردي بين الاختبارين منوسط القيمة،

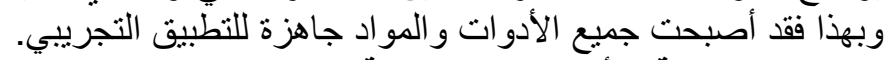

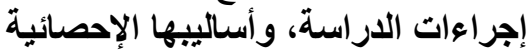

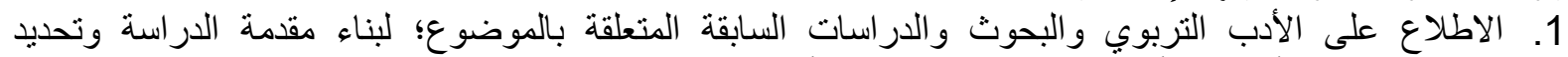

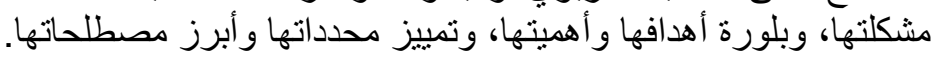
2.

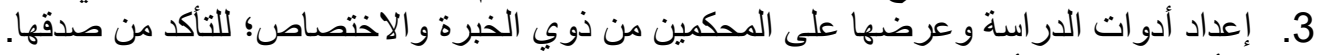

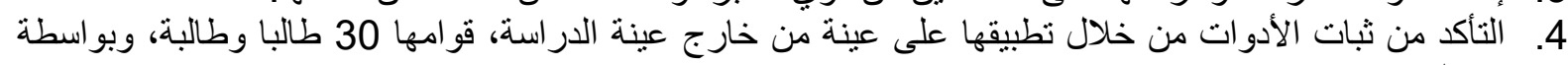

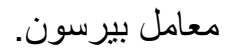

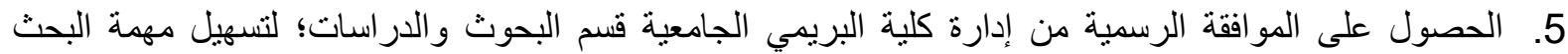

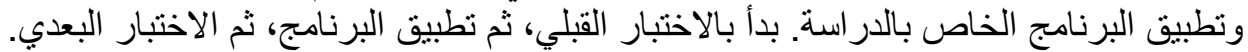

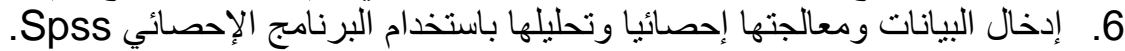

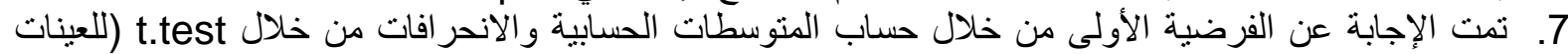

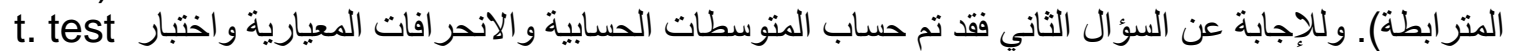

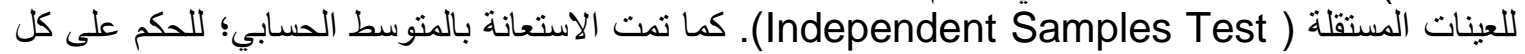

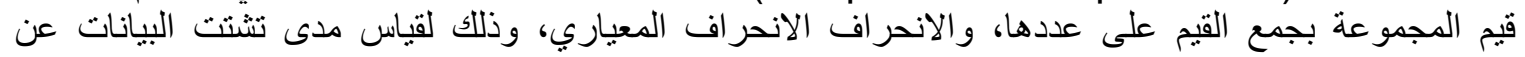
وسطها الحسابي. 8. التوصيل إلى النتائج ومناقشتها، ومن ثم تقديم التوصيات المقترحات المناسبة في ضوء النتائج.

نتائسج الاراســة ومناقشتّهـا أ) الإحصاء الوصفي جدول 3

\begin{tabular}{|c|c|c|c|}
\hline & البعدي & القبلي & البيان \\
\hline 80 & 80 & $\mathrm{~N}$ & العدد \\
\hline 25.74 & 17.89 & Mean & المتوسط \\
\hline
\end{tabular}




\begin{tabular}{|c|c|c|c|}
\hline 27.00 & 18.00 & Median & الوسيط \\
\hline 29 & $16 a$ & Mode & المنوال \\
\hline 3.676 & 5.004 & Std. Deviation & الانحر اف المعياري \\
\hline 13.513 & 25.038 & Variance & التباين \\
\hline-1.095 & .061 & Skewness & الالتو اء \\
\hline 397 & -.567 & Kurtosis & التفلطح \\
\hline
\end{tabular}

تظهر النتائج المعروضة في جدول 3 والخاصة بالإحصاءات الوصفية ونسبة تطور المتحقق في قياس الاختبار القبلي

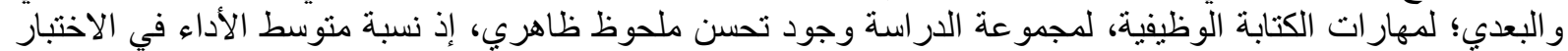

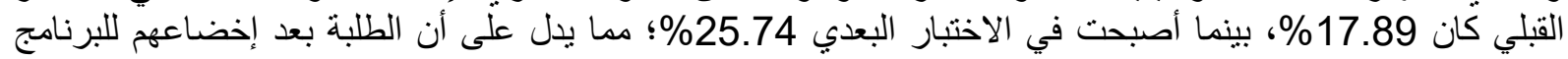

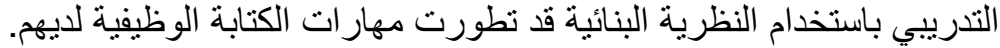

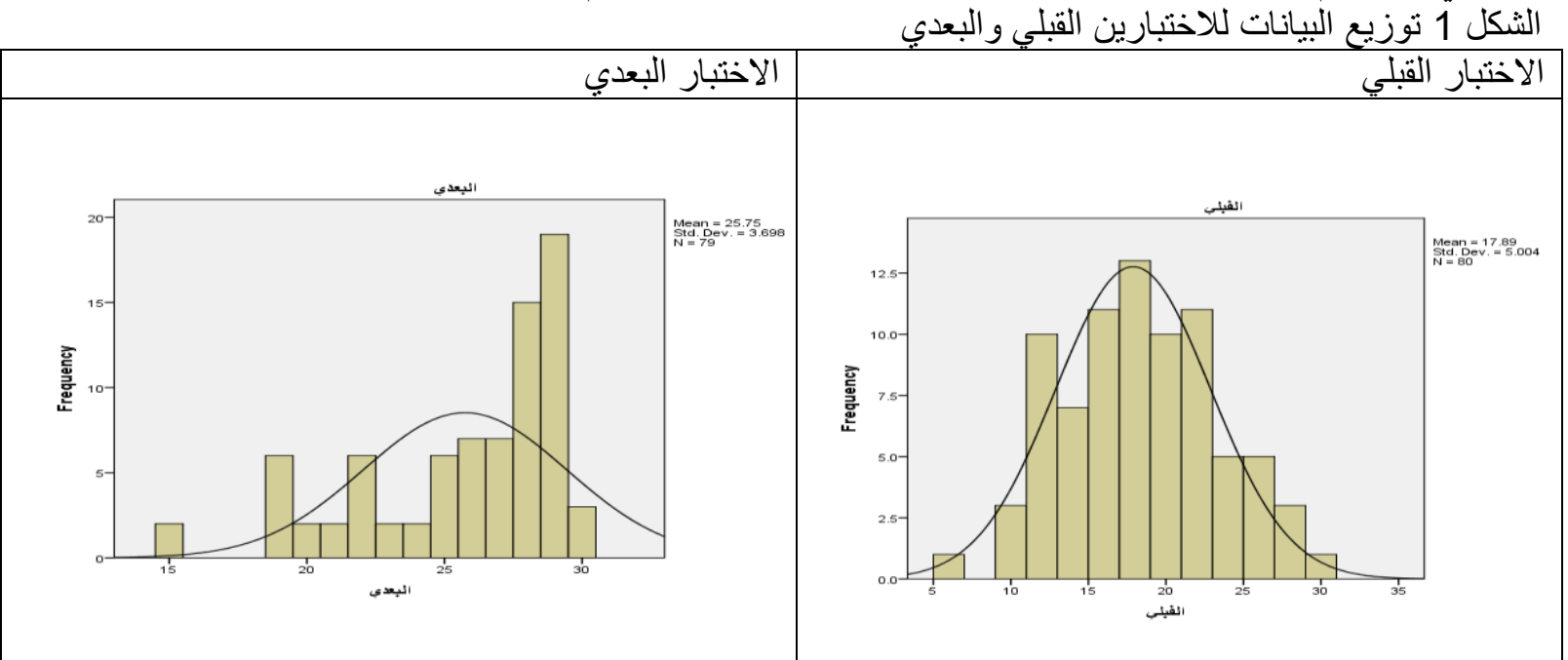

يتضح من خلال الجدول 3 و الثنكل 1 بالنسبة للاختبار القبلي أن القيم لكل من المتوسط و الوسيط والمنو ال قيم منقاربة،

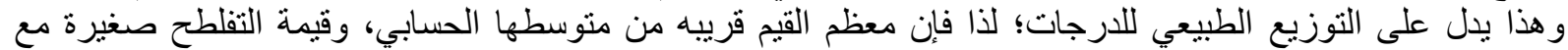

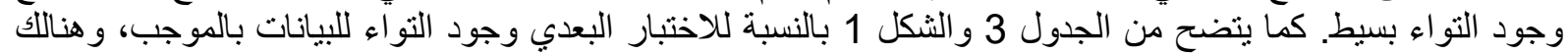

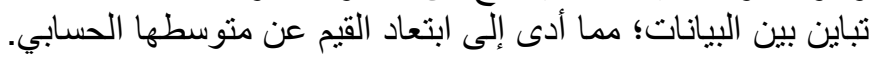

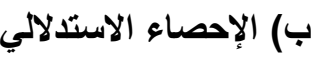

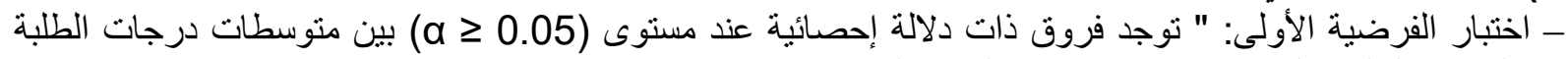

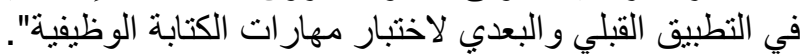
جدول 4

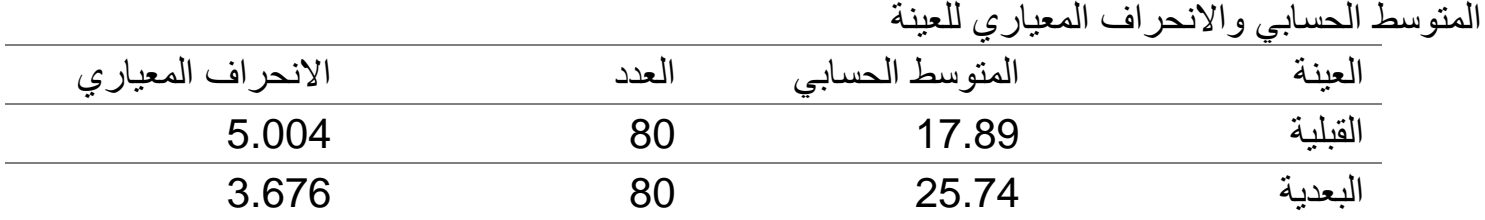

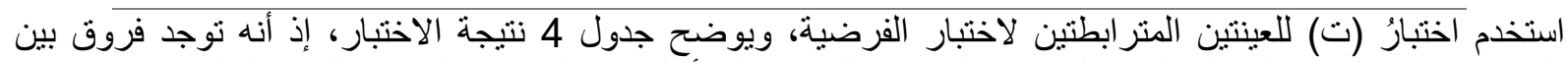

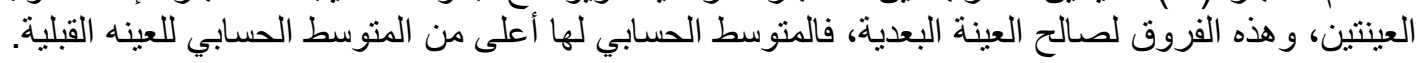




\section{THE EFFECT OF SUGGESTED TRAINING PROGRAM ON THE DEVELOPMENT OF ACADEMIC WRITING AT AL BURAIMI UNIVERSITY COLLEGE IN THE SULTANATE OF OMAN}

الفروق بين العينتين

اختبار (ت) للعينات المتر ابطة

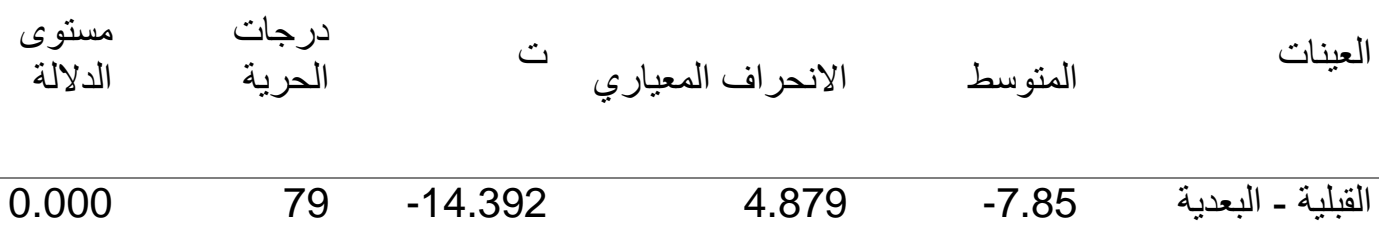

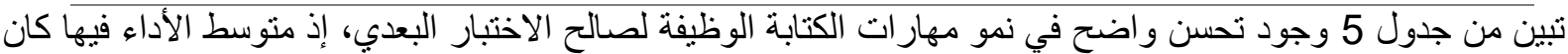

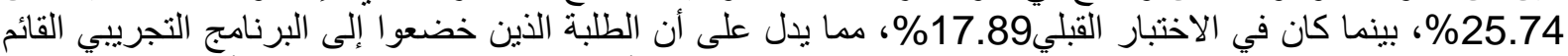

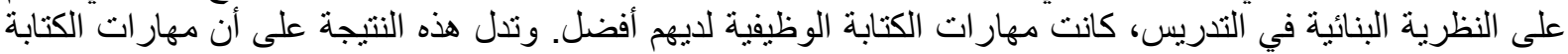

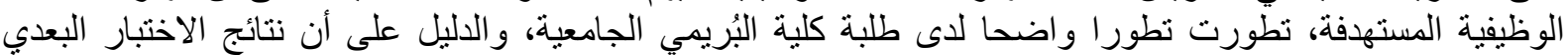

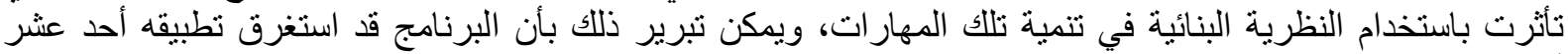

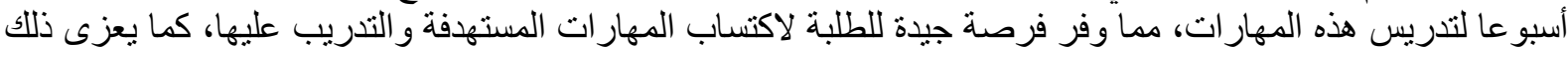

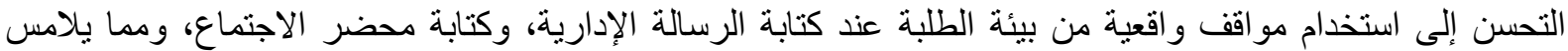

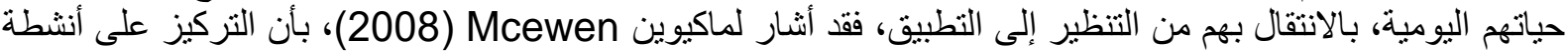

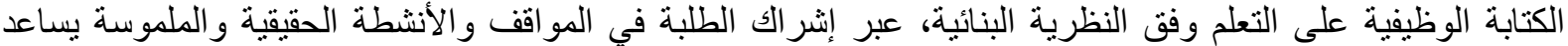

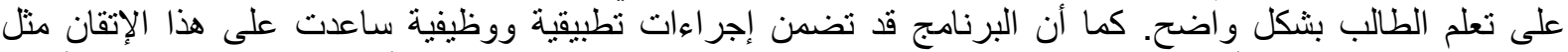

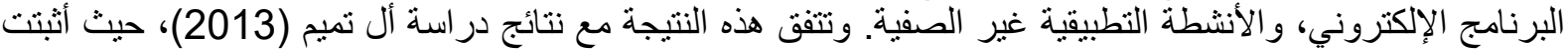
تطور المهارات الكتابية لإى الطلبة.

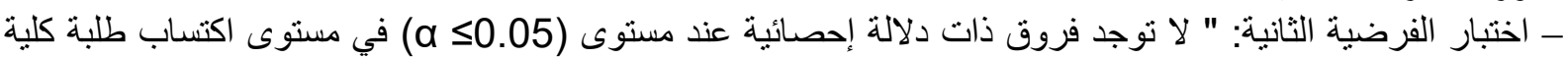

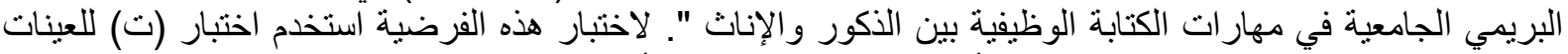

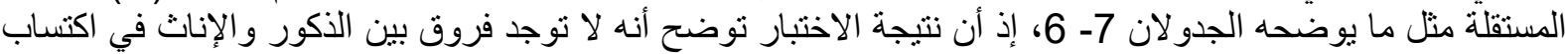

اختبار (ت) للعينات المستقلة في الكتابة الوظيفية.

\begin{tabular}{|c|c|c|c|c|c|}
\hline & نوع الجنس & 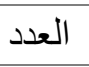 & المتوسط & الانحر اف المعياري & الخطأ المعياري للمتوسط \\
\hline \multirow{2}{*}{ البعدي } & ذكر & 40 & 26.18 & 3.601 & .569 \\
\hline & أنثى & 40 & 25.30 & 3.743 & .592 \\
\hline
\end{tabular}

يتضح من جدول 6 بأن العينة (الذكور والإناث)، مرت بالظروف نفسها في الاختبار القبلي والبعدي مثل: الأنشطة

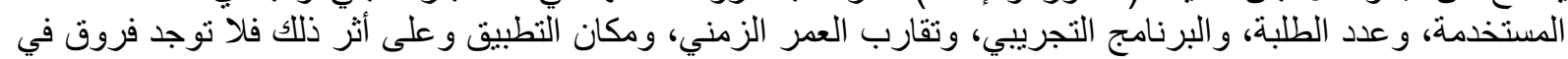

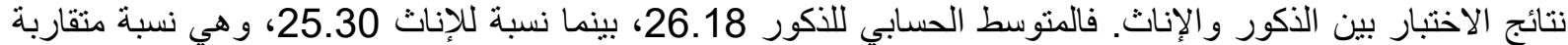
إلى حد كبير.

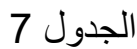
اختبار (ت) للعينات المستقلة

\begin{tabular}{rrrrrrrrr}
\hline \multirow{2}{*}{ F } & Sig & $\mathrm{t}$ & $\mathrm{df}$ & $\begin{array}{r}\text { Sig(2- } \\
\text { tailed) }\end{array}$ & $\begin{array}{r}\text { Mean } \\
\text { Dilfferenc } \\
\mathrm{e}\end{array}$ & $\begin{array}{r}\text { Std.Error } \\
\text { Differenc }\end{array}$ & Lower & Upper \\
\hline \multirow{2}{*}{760} & \multirow{2}{*}{.386} & 1.065 & 78 & .290 & .875 & .821 & -.760 & 2.510 \\
\cline { 2 - 10 } & & 1.065 & 77.884 & .290 & .875 & .821 & -.760 & 2.510 \\
\hline
\end{tabular}

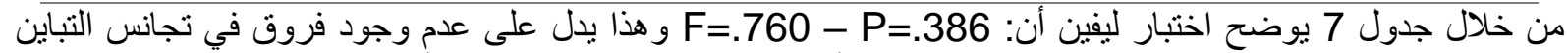

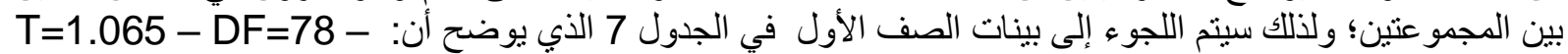

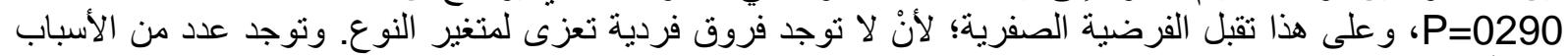

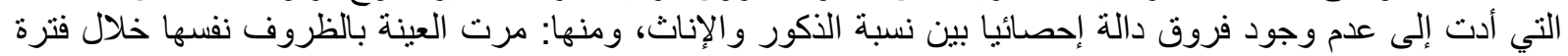


التدريب مثل: عدد الأنشطة المستخدمة ونوعيتها، وطريقة التدريس، وطريقة التقييم، وأساليب التعلم المستخدمة للنوعين

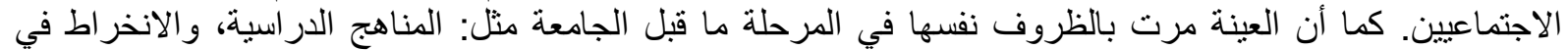

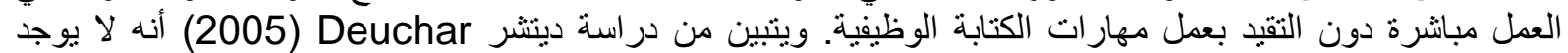

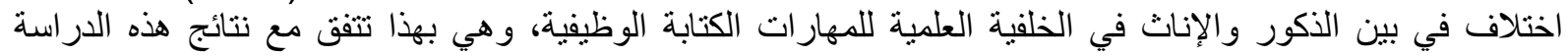

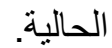

توصيات الاراسة

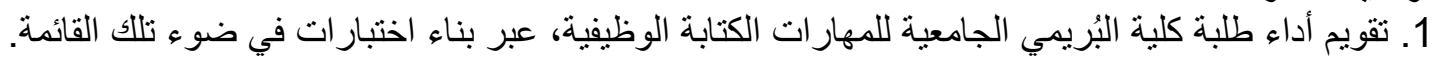
2. تزويد المحاضرين الذين يقومون بتدريس مقرر اللغة العربية في كلية البُريمي الجامعية، بقائمة المهار ات حتى تكون لهم سندا في تنفيذ المقرر بكفاءة أفضل فئل

3. عقد دورات تدريبية فعلية؛ لتدريب معلمي اللغة العربية على نظريات التعلم وخاصة النظرية البنائية. 4. دعوة كلية البريمي الجامعية إلى إقامة فعاليات نشطة؛ حتى تسهم في تنمية مهار اتلية الكتابة بشكل عام، ومهارات التية الكتابة الوظيفية بشكل خاص.

مقترحات الاراسة

1. تقويم أداء طلبة كلية البريمي الجامعية في مجالات أخرى للكتابة الوظيفية. 2. تقديم در اسة وصفية لتحديد مهار التهية الجية الكتابة الوظيفية في الجامعات والكية الكليات، في مجالات أخرى مثل: كتابة التقارير، محضر اجتماع، السير الذاتية.... 3. در اسة مقارنة بالتعلم بطريقة النظرية البنائية، في تدريس مهار ات الكتية الكتابة الوظيفية.

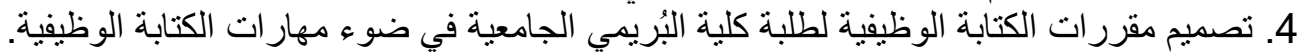

مصادر الاراسة ومراجعها أبو غز الة، طلال. (2019). الطلاقة في مهار ات اللغة العربية. طلال أبو غزالة التة للترجمة و التوزيع و النشر.

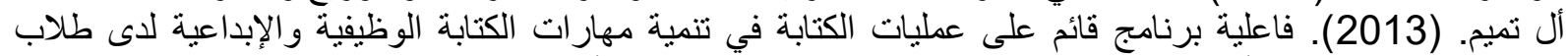

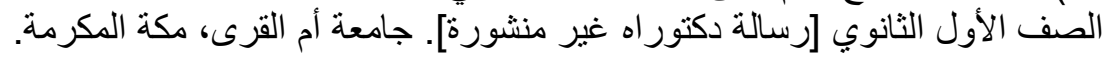
تميم، راجح حسين. (2015). الكتابة الوظيفية، دار الكتاب الجنابة الجامعية.

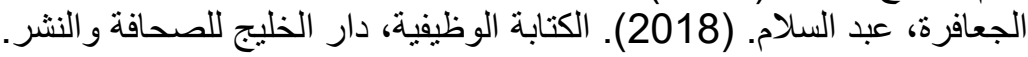
الحامدي، محمد. (2012). المواصفات العامة للكتاب المدرسي السعودي العية (ط.3). وزارة المعارف بالمملكة العربية

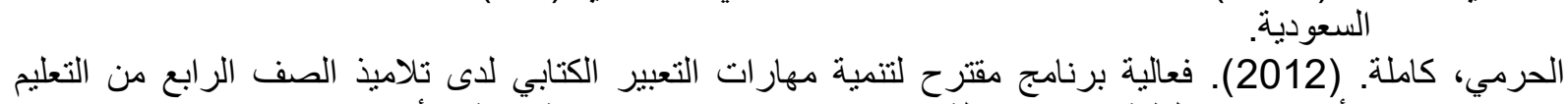

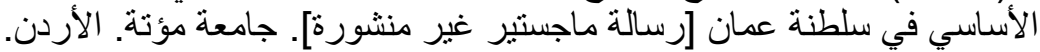

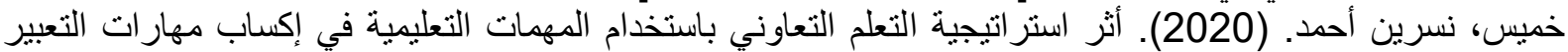

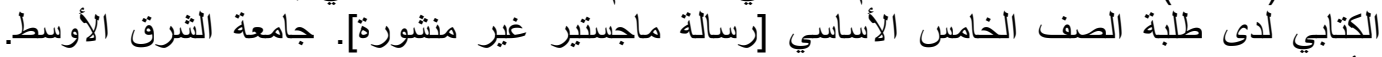

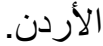

الدبوس، جو اهر محمد. (2003). الاردي. (القاموس التربوي. مجلس النشر العلمي. زايد، فهد. (2008). الكتابة: فنونها أفنانها. دار يافأ.

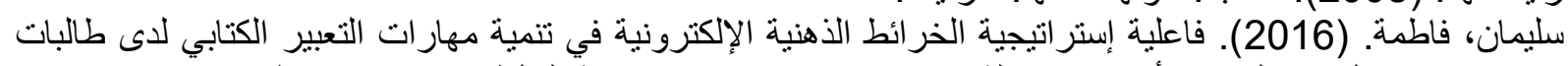

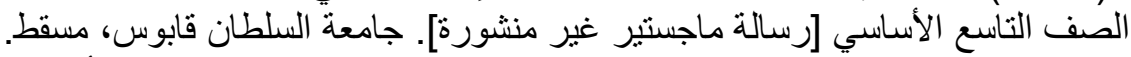

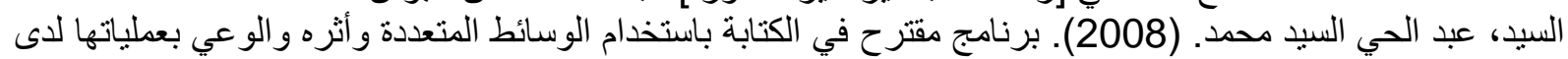

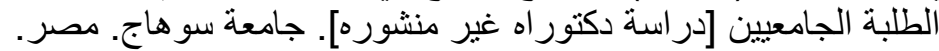

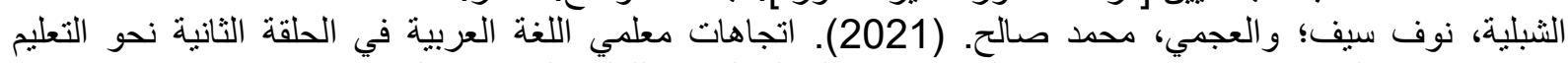

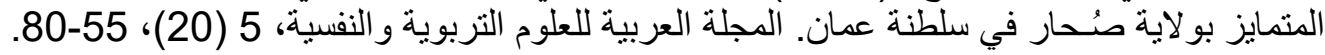

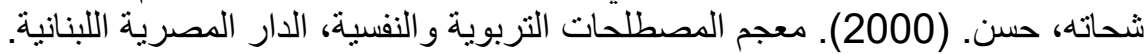

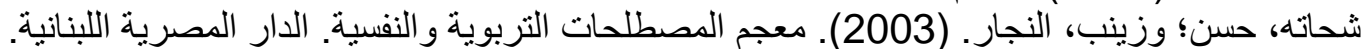

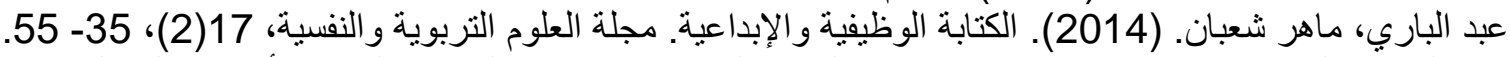

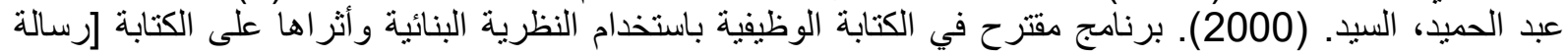

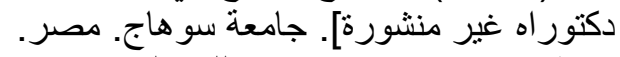
عبد الله، علي مصطفى. (2014). مهار ات اللغة العربية، دار أرام. 
العجمي، محمد صالح، والحوسنية، سميحة علي. (2019). أثر التدريس بأسلوب القصة القصيرة في تنميـة الوعي القيمي

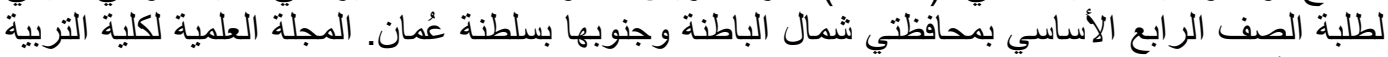

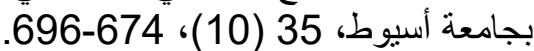

العجمي، معصومة. (2015، فبراير 25-23). الكتابة تعليما وتعلما. ورقة عمل قدمت في فعاليات ندوة اللغة العربية الثالثة، مسقط: سلطنة عمان.

عصر، حسني عبد الباري. (2000). الاتجاهات الحديثة لتدريس اللغة العربية. مركز الإسكندرية للكتاب.

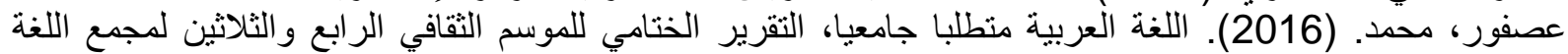
العربية الأردني.

عطية، محسن.(2007). تدريس اللغة العربية في ضوء الكية الكفايات الأدائية. دار المناهج للنشر و التوزيع.

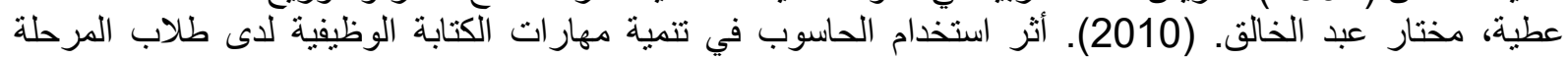

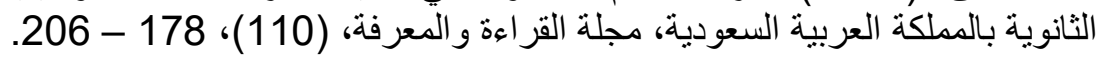

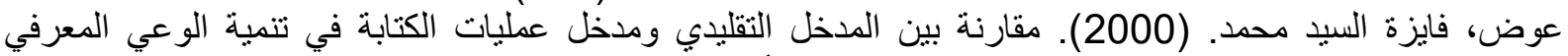

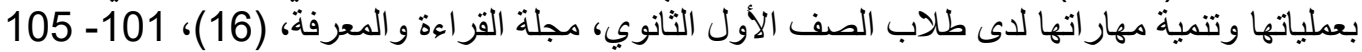

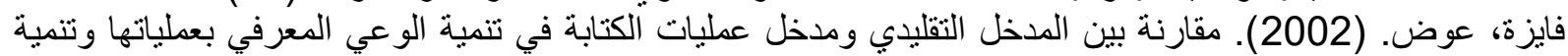

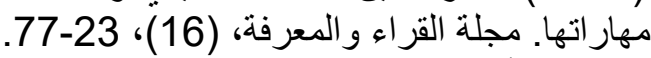

فتحي، يونس. (2000). أساسيات تعليم اللغة العربية والتربية (2016)، الدينة

فجال، عبد الله بن محمود. (2016) (2016). أثثر برنامج تدريبي قائم على تنتية دارية المهارات الكتابية لدى طلية طلبة السنة التحضيرية

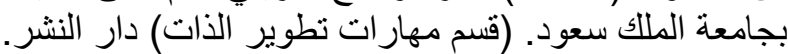

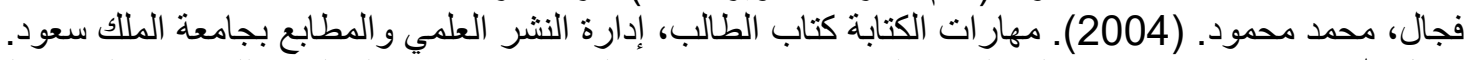

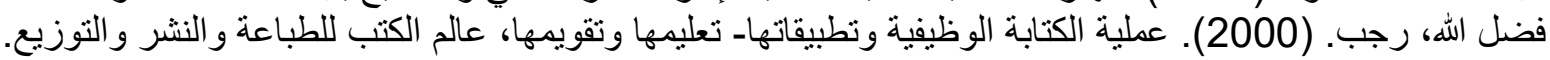

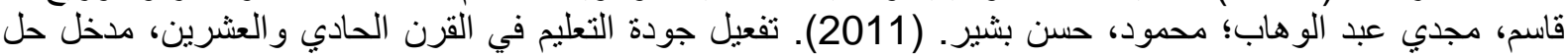
المشكلات: دار الفكر العربي.

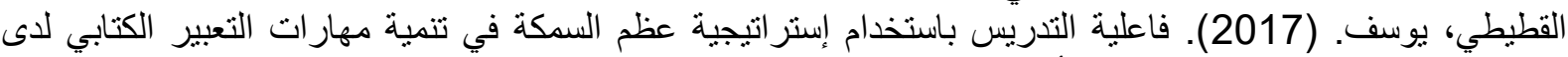
طلاب الصف الثامن الأساسي في سلطنة عمان [رسالة ماجستير غير منشورة]. جامعة السلطان قابوس، التئ

\section{مسقط.}

لافي. سند. (2005). الكتابة الوظيفية، جامعة نايف العربية للعلوم الأمنية.

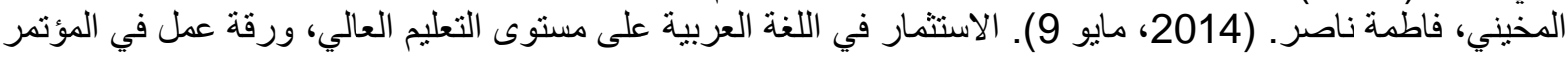

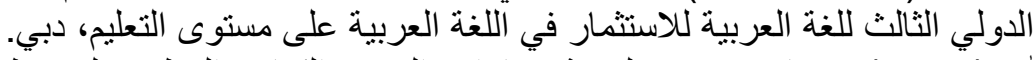

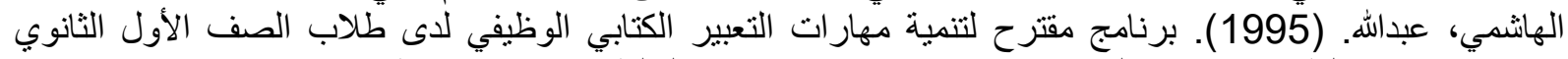

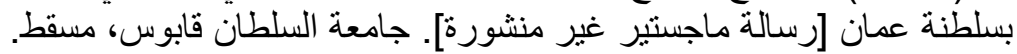

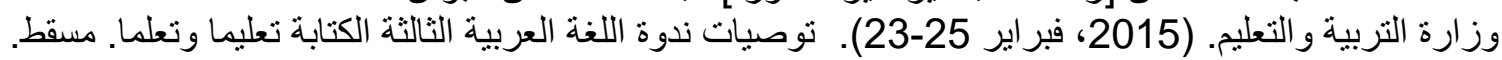

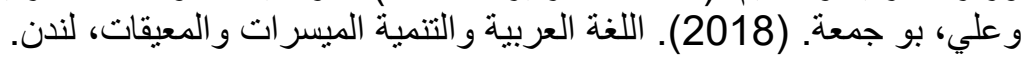

Alan, E Kazdin .2000) .Encyclopedia of Psychology, Vol. .5, American Psychological Association, London: Oxford University Press.

Deuchar, R. (2005). Fantasy or redlity? The use of enterprise in education as an alternative to simulated and imaginary contexts for raising pupil attainment in functional writing. Educational review, 57 (1), 91-144

Fosnot, Catherine. (2013). Constructivism: Theory, Perspectives, and Practice (2ed). Teachers College Press.

Gert, Rijlaarsdam; Huub, Bergh; Miche, Couzijn. (2005). Effective Learning and Teaching of Writing: A Handbook of Writing in Education. Kluwer Academic Publishers

Mcewen, B.C. (2008). Improving the writing skills of business majors: The collective responsibility of all courses and professors. Libraries Unlimited.

Oliveira, Luciana; Silva, Tony. (2016). Second Language Writing in Elementary Classrooms. Palgrave Macmillan. 